\title{
Outlining the Offshore Marine Environment and Mammal Habitation with the Changing Climate: the case of Ghana's waters
}

Anthony Djaba Sackey ( $\sim$ deckcadetsackey09@gmail.com )

RROC Industrial Limited

Benjamin Lantei Lamptey

University of Leeds

Patrick Ofori-Danson

University of Ghana

\section{Research Article}

Keywords: Environmental Baseline Survey, Gulf of Guinea, Marine Environment, Marine Ecology

Posted Date: March 10th, 2021

DOI: https://doi.org/10.21203/rs.3.rs-311527/v1

License: (1) This work is licensed under a Creative Commons Attribution 4.0 International License. Read Full License 


\section{Abstract}

Understanding environmental baseline parameters within Gulf of Guinea offshore areas- as relevant delineating conditions favourably ensuring the survival of marine life bounded within was examined against environmental baseline surveys (EBS) conducted during the Environmental Impact Assessment (EIA) by licensed oil and gas operators of the region. The case of the EBS within Ghana's western basin is mainly because offshore marine habitation over a decade has seen a rise in anthropogenic activities. Current concerns span pollution, over-exploitation of natural resources, air emissions, growing anthropogenic activity, and climate change. A series of samplings were taking at essential offshore and coastal facility locations to investigate baseline ocean environment; understand the nature of ecology and identify issues of vulnerabilities that could ensure destructive tendencies.

The paper observes EBS conditions were consistent with findings of EIAs. The tropical nature of the region meant high radiation influx from the sun- leading to the thermal insulation of the area. Temperatures recorded are a direct function of solar energy absorbed in the atmosphere -delimiting humidity over infrared wave outputs, atmospheric precipitations and occasional poor visibility. Absorbed heat energy in the ocean depicted a generalised thermocline at the surface. Several surfaces and underwater factors including wind influenced the salinity, and temperature along water-depth, sound velocity, and dissolved oxygen concentrations - useful to marine animals such as turtles, seagull, pilot whales, dolphins, and sharks; clustered along with various webs of the food chain. The main challenge to the environment was the concerns of growing anthropogenic activities, plastic pollution and oil spills from operations and possible blowouts.

\section{Introduction}

World over, there is a genuine concern for the environment - stemming from several decades of work undertaken by several scientists and environmental activist, who believe there is clear proof that the environment is changing and changing for the worse. Efforts at addressing these concerns, however, have become more political and emotional than the use of standard scientific application and technology aimed at reversing predicted trends. Therefore, for the past two decades, very little progress has been made. Nevertheless, there is no doubt that a changing environment does beset with naturally devastating consequences. Hence, in Ghana, critical in reflection to issues within her maritime environment is the recent rise of carcasses of dead whales found along the beaches of coastal communities, thus fostering Ghana EPA's concerns - predicting many more deaths to come (Koranteng, 2017), with the cause still to be determined. There is also the concern of sea-level rise encroaching and inundating coastal communities, increasing coastal erosions, lost in coastal eco biodiversity, the depleting fish stocks in the adjacent ocean. Many have attributed these changes occurring in the natural environment to human activities (National Geographic Society, 2020). It is far too common to find plastic pollution across major coastlines of Ghana (Plastic Punch, 2020) today, despite the enormous humanitarian efforts by environmentalist and NGOs (e.g. the Plastic Punch organisation based in Accra) on the beach clean-up exercises.

The current concerns range from pollution, over-exploitation of natural resources, coastal or offshore marine developments, erosion. Therefore, grounding the concerns for biodiversity, environment distraction and the desire for wildlife conservations, will be the need to understand Ghana's marine environment better. Thus the marine environment of Ghana forms part of the Gulf of Guinea bay and is today actively utilised for socio-economic, cultural and political gains. The importance of conserving marine and notable coastal eco biodiversity areas (such as Amansuri Wetlands; and Domini Lagoon within Ghana, and internationally, Grand-Bassam Ramsar; N'Ganda N'Ganda Ramsar; and Iles Ehotilé-Essouman Ramsar of a neighbouring country, Ivory Coast (ERM/TGL, 2014)) cannot be overemphasised particularly with the rising record of infrastructure developments springing up near shore and offshore areas along the gulf stretch. These changes include development on new hydrocarbon license blocks, massive port expansions covering several square kilometres of sea and landmass (such as the Tema and Takoradi port expansion projects, and the pecan oil field development offshore). In coastal areas, the commencement of expansion works to port facilities appear inevitable as seen with the two commercial seaports in Tema and Takoradi. This development was to shore-up capacity directed at hosting dedicated offshore-onshore terminals for the oil and gas industry [Ghana National Chamber of Commerce and Industry, GNCCI (2017)]. These developments are in tandem with observations from countries bound to the south Atlantic, according to David Rogers' article (Global Construction Review, 2017). Some of the developments happening beside the various port expansions (Mitchell F., 2020) along with West Africa, includes subsea oil and gas pipelines from offshore areas to onshore receptacles (Ghana National Gas, GNG, 2021), offshore FPSO unit installations, subsea installations, oil refinery plants.

The effect of all these projects on the natural environment is in no way hidden. Therefore, specific queries explored in this section of the study are as follows. What is the nature of the marine and coastal environment? What type of marine and coastal habitations contribute to the biodiversity found in the area? Is there a visible threat to the various natural habitats? What are the actions taking by authorities to ensure eco biodiversity sustenance? The study in resolving these questions will investigate the baseline knowledge of the marine and coastal biodiversity and ocean environment. The study will also proceed to identify vulnerabilities found in the natural environment while evaluating regulations and measures in place to ensure the destructive impact are minimized. Therefore the study herewith, asserts that

Page 2/23 
results obtained will fill the gap of knowledge relevant to understanding the dynamics of the meteorological-oceanic environment, biodiversity, and eco sustenance within the Gulf of Guinea bay.

\section{Materials And Methods}

\subsection{Study Area}

Though the entire Gulf of Guinea bay remains the subject of the study, the focus was on specific locations within the western basin (Tano Cape Three Point) of Ghana's hydrocarbon reserves (see Fig. 1). These areas were particularly, crucial locations based on the region's subjection to growing anthropogenic activities. At the Jubilee area, according to ERM-TGL, (2009), annual wind direction and speed characterising the offshore area are relatively constant. The Jubilee field, which straddles Deep Water Tano and the West Cape Three Points license blocks -located $60 \mathrm{~km}$ away from the southern coast of Ghana.

Adjacent the DWT/WCTP license block is the OCTP license block stretching northward near the coast with water depths under 1000 meters. This area is more within the continental shelf reach and towards the coast. To the south and east of WCTP and OCTP Blocks areas respectively, lies the Pecan oil fields discoveries situated within the DWT/CTP block (on the continental slope area), and the Afina- 1 Well discovery within WCTP Block 2 license area. The same meteorological features broadly characterise all these areas (ERM-TGL, 2009).

\subsection{Methodology}

The study here largely remained descriptive - relying on both qualitative and quantitative data obtained through various means of measurements in the field. This approach relied on the use of marine vessels in accessing remote locations, along with specialised sets of equipment, including ROVs operated by vessel staff. The study also made use of combined qualitative and quantitative data gathering techniques over the 2020 four-month-period field undertakings. The parameters tested in line with the natural marine environment include; (a) meteorological, and (b) oceanographic samples, thus, providing an outlook of the area environmental dynamics against the specie habitats - thus forming part of the broad ecosystem of the region. The region is also believed to host the most recently discovered coral reef along the coast of Ghana. Thus suggesting a strong relationship between reef sight and surrounding habitats.

\subsection{Data Sources and Analysis}

\subsubsection{Study Design}

Though the entire region of the western basin is the focus in this study, due to limited access and resource at the researchers' disposal at the time of the 2020 study, the hydrographical profiling aspect of the environment was relatively limited to locations within the Jubilee oil field unlike meteorological data taken every six hours at any point of the marine vessel locations in the study region. Thus during field operations and transits between the port and offshore facilities.

The survey design shown in Fig 2 was planned to incorporate previous EBS studies during the analysis stage as the fundamental description of the area. Meteorological data covered daily recordings taken at all vessel locations while at the site in the year 2020.

Ocean data gathered for EBS analysis included a sampling of station locations selected during the 2020 surf operations on the Jubilee field [see Fig. 2]. Both night time and daytime data were gathered.

\subsubsection{Field Methods}

Data Gathering process: is defined by the nature and type of data parameter sort and utilised in the analysis process. Qualitative data, in this regard, was obtained through interviews, references to internal documents, and site observation. The quantitative data, however, which is in reference to the primary parameters of the study, involved the deployment of remotely operated vehicles, position beacons and access to data from a stationed weather buoy installed and operated by a third-party institution. The environmental variables considered are; Conductivity, Ocean Current, Visibility, Waves, Wind, Temperature, Density, Dissolved Oxygen, Water Depths, Salinity and Velocity. Each of these variables uniquely helps define the environment. Sighting observations conducted were also for the marine animal presence and visibility levels at surfacing. The instrument used in gathering data on salinity, temperature, water depth was Subsea 7 ACV09 SCU. Handheld binoculars as well as bridge equipment such as GPS, Gyro was also used. Secondary quantitative data from previous sample stations were also considered and retrieved from supplementary published EIA reports.

\section{Data Analysis}


Climate and Meteorological Impression: this included wind, atmosphere pressure, visibility (fog/ midst), atmospheric temperature and ocean surface (wave height and direction) conditions observed and recorded. Analysis of wind conditions makes use of the Lake Environmental Software Version 7.0.0., (1998-2011) in Windows 10 OS. The study modelled for a viable wind rose and wind class frequency distributions over the data gathered for the period of the 10th of January to the 28th of March, 2020- taking into account wind speed and direction over an hourly interval. Atmospheric pressure, temperature, visibility, and ocean surface conditions, however, were analysed using Microsoft Excel (2013); in deducing graphical information of the various data obtained.

Ocean Hydrographical Visualisation and Modelling: took into account key conditions (Water depth, Ocean temperature, Salinity or Conductivity and Density) measured and recorded over a selected number of locations. Densities computed were by UNESCO Equation of State of Seawater (EOS-80) Formula, and in some cases, Salinity computed was based on Weiss (1970) set of equations (Benson and Krause, 1980 and 1984) from specific conductivity readings. The general relationships given are below;

$$
[\mathrm{DO}]=\mathrm{DO}_{0} * \mathrm{~F}_{\mathrm{g}} * \mathrm{~F}_{\mathrm{p}},
$$

Where, dissolved oxygen (DO) concentration in $\mathrm{mg} / \mathrm{L}$ represented describes a baseline concentration in freshwater (DOo) multiplied by salinity $(\mathrm{Fs})$ and pressure correction factor $(\mathrm{Fp})$. Additionally, the salinity and the pressure correction factor are a function of salinity and barometric pressure respectively. The U.S

Geological Survey (USGS) (2011) reiterated that all three terms are a function of water temperature. Benson and Krause equation of DO is in equation (2) below;

$$
D O_{o}=\exp \left[-139.34411+\frac{1.575701 \times 10^{5}}{T}-\frac{6.642308 \times 10^{7}}{T^{2}}+\frac{1.243800 \times 10^{10}}{T^{3}}-\frac{8.621949 \times 10^{11}}{T^{4}}\right]
$$

OR

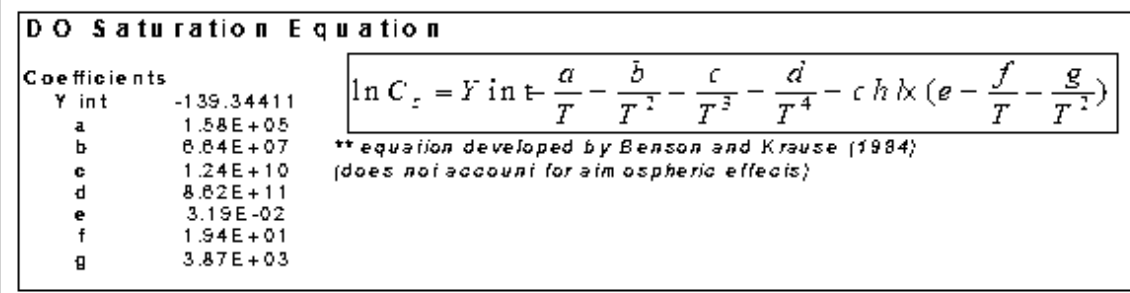

Where $T$ is the water temperature in $\operatorname{Kelvin}\left(T=t\left({ }^{\circ} \mathrm{C}\right)+273.15\right)$. The Benson and Krause salinity factor is:

$$
F_{S}=\exp \left|-S *\left(0.017674-\frac{10.754}{T}+\frac{2140.7}{T^{2}}\right)\right| \ldots \operatorname{eqn}(3)
$$

Where $\mathrm{S}$ is salinity in parts per thousands (\%0), $\mathrm{T}$ is temperature in Kelvin. Salinity estimated, however, is based on its relationship with specific electric conductivity given as;

$$
S=5.572 \times 10^{-4}(S C)+2.02 \times 10^{-9}(S C) \ldots e q n 4
$$

Where SC is specific conductance's measured in microsiemens per centimeter $(\mu \mathrm{S} / \mathrm{cm})$ over a wide range of temperature $\left(0-40^{\circ} \mathrm{C}\right)$ and specific conductance $(0-67,000 \mu \mathrm{S} / \mathrm{cm})$. Refer to USGS (2011) Office of Water Quality Technical Memorandum 2011.03: Change to Solubility Equations for Oxygen in Water, for the entire equations applicable for the rest of elements applied in equation (1).

The analysis concludes by deducing a graphical relationship between D.O., Ocean temperature (degree Celcius), Salinity [Practical Salinity Unit (psu)] or Conductivity (micro siemens per centimetre), Density (kg/m3) and the various Water depths of the selected study locations. The 2020 stations sampling data will be juxtaposed to a reanalysed 2008 and 2011 EBS studies from the DWT and WCTP blocks of the study region and along gas export pipeline all the way to shore base facility conducted over water column sample. The 2011 samples are of three selected locations thus from near-surface to 100-m water depths at Station 4 (profiled on the 26th of March at 1,500meter water depth), Station 10 (profiled on the 27th of March at 1000meter water depth), and sample along the gas export line from near-surface and near-bottom ( $<5 \mathrm{~m}$ to the seabed) at station C1 (profiled the 28th of March at 77meter water depth)). A comparison to the findings of the 2008 EIA EBS and 2020 EBS hydrographic data will be evaluated graphically. During the 2008 WCTP EBS EIA surveys by ERM-TGL, close to eighty (80) sample locations were selected however less that number was sampled due to insufficient data recovery at specific locations and inaccessibility as a result of extreme shallow depths. Therefore, this study highlights 14 stations of previous sample data of those 
locations (in the above map) from which graphical reanalysis would evaluate in comparison to the 2020 samples. (See supplementary material for the samples data).

\section{Results}

4.1 The Atmospheric Conditions of the Marine and Coastal Environment

Stewart R. H., (2008 pp39) noted that because the atmosphere drives the ocean, while the ocean drives the atmosphere, it is imperative to consider the ocean and atmosphere as a 'coupled dynamic system'.

Observation of Wind Patterns: In general, the atmospheric characteristics underlining the coastal and marine environment of Ghana have minimal variations, thus according to earlier EIA baseline studies conducted by ERM/TGL (2009) and ESL Consulting/ENI S.p.A (2015). The ERM/TGL (2009), asserts for example that, primarily, observed winds generated are of the southwest quadrant -and thus having a maximum non-squall attribute of $10 \mathrm{~m} / \mathrm{s}$ wind speed. Fig. 3 also shows results compiled of daily wind from the study region during the study. Winds on the sea surface usually represent velocity structure near the base of the atmospheric boundary layer (ABL) and are directly linked to circulations above the ABL with patterns reflecting the entire structure of the atmospheric general. Therefore, at low latitudes, trade winds dominate while the easterlies winds dominate the Equator in both the Pacific and Atlantic Oceans (Rui Xin Huang, 2017; 2015).

Again, the assertion from ERM/TGL (2009) and ESL Consulting/ENI S.p.A (2015) is in agreement with the findings of the study depicted in Fig. 3 and 4, which showed an intense wind activity directed within the southwest quadrant of the wind rose, with maldistribution within the northwest. Again, 41.8 per cent wind speed recorded between the 10th of January and the 28th of March 2020 study period, fell within the frequency range of 7-11 knots. ERM/TGL (2009) notes that these wind characteristics accordingly, beset the fairly consistent year-round wind patterns of the region. Squall[1] events observed, however, have been attributed to thunderstorm generating extreme wind conditions. Thus, approximately 15 - 30 squall events are expected yearly though with a short duration. Implicitly, over the ocean, they end up with weaker surface current and low wave heights (ERM/TGL, 2009). For coastal areas, with time, wind stress changes over most parts of the world's oceans to a noticeable seasonal cycle (Rui Xin Huang, 2017; 2015). It was observed that the coastline areas show high levels of atmospheric salt precipitations largely due to high temperature and convectional wind activities near the surface.

Observed Atmospheric (Barometric) Pressure: the period of January to March 2020 for which the study carried out before the covid-19 pandemic (Verdict Media Limited, 2020), showed relatively, a minimum and maximum sea-level pressure (MSLP) range of 1000mbar and $1010 \mathrm{mbar}$ (shown in Figure 5) - thus, below the standard average sea-level pressure of 1013.325mbar (101.325kPa; 29.92 inches of mercury; $760.00 \mathrm{mmHg}$ per the International Standard Atmosphere (ISA). The GCNS (2009); Stewart (2008) noted that pressure distribution around the earth surface results from the heating sun (insolation) which varies with latitude.

From the graph, the least sea-level pressure of $1000 \mathrm{mbar}$ recorded was by the noon hour (GMT) midday. Pressures recorded remained reasonably low -influencing atmospheric activities (such as cloud and winds resulting in the occasional rainfalls observed over the study period). The 6:00 am, 12:00 am and 12:00 pm periods recorded as high as 1010mbar of barometric pressure- with a Mean (average) at $1006.578947 \mathrm{mbar}$. The region under study lies near the equatorial latitude, and hence, tends to benefit from the massive influx of the sun's thermal insulation - resulting in surface heating. The area, therefore, lies within the 'Equatorial Low' (GCNS GCM, 2009). These recorded pressure are said to influence the amount of dissolved oxygen along the ocean column which helps maintain the function living of organisms that require oxygen for metabolism.

Observed Conditions of Visibility: in navigational terms, visibility means the extent to which an individual either on the navigational bridge or deck watch-keeping can maintain a visual lookout for an object over distances on ocean up to horizon form a marine vessel or platform. Brown and Brown, (2016) explains this as the "term used in describing the transparency of the atmosphere, and defined by the maximum distance at which a suitable object is seen." Conditions such as fog, sea smoke and massive rainstorm are a few atmospheric processes that contribute to reducing visibility during the day. Implicitly, the knowledge of the level of visibility on the ocean at any particular time is paramount in ensuring the safety of life, property and environment during navigation. Figure 6 is a graph indicating a visibility pattern over the study region for the study period.

Though visibility recorded was relatively good (mostly) with a median of $10 \mathrm{~nm}$, the minimum visibility recorded over the period was under 2nautical miles $(\mathrm{nm})$ in January and February. The reduced visibility recorded can be attributed to both radiation and advection fog activity. 
The radiation fog influenced the visibility of the vessel at the Takoradi port location from the 10 through to the $12^{\text {th }}$ (during the $P .0$. vessel mobilisation). Unlike the radiation fog formation occurring at the coast of Ghana, the remoteness of the condition's location over 60kilometers offshore, suggested an advection fog formation (Brown and Brown, 2016) -thus, consistent with the low visibility through the first and second weeks of February heading into March (marking the summer cold sea temperatures). This condition poor visibility, therefore, may put animals; surfacing on the water in the region, at risk of strikes from speeding marine vessels. Maximum visibility was as high as $12 \mathrm{~nm}$, though did vary over $10 \mathrm{~nm}$ for the study period. The period under study also marked the upwelling season characterising the feeding behaviour of marine mammals in the area -suggesting the imminence of animal surfacing behaviour.

Atmospheric temperature: which is the measure of the degree of hotness or coldness of an object or place, was primarily crucial in this study in understanding the level of thermal energy transfer occurring above the ocean surface within the study location. Stewart R. $\mathrm{H}$. (2008) in fact, asserted that only a fifth of the solar energy released by the sun is absorbed directly into the atmosphere as either evaporation or infrared wave energy. Therefore, the temperature seen in Figure 7 is a recorded function of these two primary atmospheric energy delineating the atmospheric dynamics of the study region within the subtropical area.

From the graph, temperatures from the 10 th of January and 28 th of March at 0600 am (hr) range between $27^{0} \mathrm{C}$ and $30^{\circ} \mathrm{C}$ with a Median of $29^{\circ} \mathrm{C}$. Similarly, the $1200 \mathrm{pm}(\mathrm{hr}), 1800 \mathrm{pm}(\mathrm{hr})$, and $0000 \mathrm{am}(\mathrm{hr})$ recorded minimum and maximum temperatures of $26^{\circ} \mathrm{C}-32^{\circ} \mathrm{C}(\mathrm{a}$ median of $30^{\circ} \mathrm{C}$ ); $26^{\circ} \mathrm{C}-31^{\circ} \mathrm{C}$ (a median of $30^{\circ} \mathrm{C}$ ); and $28^{\circ} \mathrm{C}-30^{\circ} \mathrm{C}$ (a median of $29.5^{\circ} \mathrm{C}$ ), respectively. These results are fairly consistent with subtropic temperatures readings - suggesting some levels of active humidity. These temperatures conditionally influence marine animal's surfacing and deep-dives from time to time.

\subsection{The Ocean Surface Conditions}

Observed Wave Activity: the waves were driven by surface wind interactions - generating significant wave heights up to $1.4 \mathrm{~meters}$. Waves with a median of 0.9 meters. These are represented in Figure 8 . Wave patterns offshore and near coast showed the similar characteristic of small amplitudes, however, multi-directional offshore compared to near coast waves that ended up on the beachlines. Given that smallscale surface waves first are generated from wind stress; subsequently, via 'wave-wave interaction,' energy released in the phase space resulting in surface waves with a long wavelength and large amplitude were not commonly seen in the region. This, Rui Xin Huang (2017; 2015) compared to larger-scale currents, that indicated surface waves- thus, concluding small-scale wave is the problem.

The maximum recorded wave was over 2 meters in height for January through to March 2020. These waves characterised were associated with the southwestern quadrant - the same pattern as with winds. However, wave periods over time are subject to dynamic instability in which stable ocean waves become unstable due to velocity shear.

Observed Ocean Current: activities of ocean current observed was of both surface and water current conditions, primarily referred to as Guinea Surface Current and Guinea Underwater Current. The surface current measured was from the 0meter ocean depth at the surface to a depth of 40 meters. Figure 9 shows both the amplitude and direction of the water surface current. The direction of the surface current showed a powerful feature within the southwest and northwest quadrants. According to GCNS (2009), surface currents are mainly winddriven (see also Fig. 3 and 4) -a conduit of surface friction at a right angle due to the Coriolis Effect causing the current heading in the westerly direction. The patterns observed compared favourably with ERM/TGL (2009) and ESL Consulting/ENI (2015) findings, as far as the depiction of global surface ocean current from GCNS (2009), is of concern.

Again, Stewart (2008 pp51) notes that tropical ocean currents, particularly of the Atlantic, play a vital role in the unsteady transportation of thermal energy (solar energy stored in the ocean) from summer to winter during the amelioration of the earth's climate. This reason is also critical to understanding climate change.

The dynamics between the current and waves observed in the earlier graphs was paramount to understanding ocean stability. Hitherto, Stewart (2008 pp129) stressed that because oceans appear strongly stratified with weaker currents, turbulent mixing remains intermittent and are rare. This situation generates a period of the stable and unstable ocean surface from frequent wave formations and breaks.

\subsection{The Ocean Structure and Marine Ecosystem}

The ocean is a natural supporter of various life forms - with the capabilities to thrive in its unique environment. However, the life support of most living mammal or organisms relies on fundamental environmental conditions that include Oxygen, lamination (Sunlight), water, favourable shelter and food sources. The ocean, unlike rivers and streams that are freshwater sources for animals within, living organism in 
the ocean, are forced to contend with a high concentration of salts. The study primarily examined the relationship of salinity concentration (psu), dissolved oxygen (D.O.) concentration (mg/L at 100\% saturation level), Density (D) and temperature variations (synonymous to radiated heated energy from sunlight) over water depth as characteristic supportive of marine lifeforms in terms of feeding, habitat, and procreation.

\subsubsection{Water Column and Hydrographical Data}

While previous environmental baseline surveys (EBS) conducted in EIA over the region on the various oil fields and surrounding areas have determined to some level the baseline conditions of the environment. Thus on biological, chemical and physical importance before field developments, it also identifies ecosystem parameters sensitive to impending changes; thus, all as part of meeting environmental impact assessment requirement, the EBS sampling locations were selected by the oil field license operators in their EIA EBS. The scientists factored in; daily water column profiling, and seafloor sediment sampling (CSA International, Inc. /TGL, 2011).

The summary hydrographic results of the 2011 EBS on the DWT block by CSA International, Inc. /TGL, (2011) which is also within the field demarcation of this study, have been presented in detail alongside the findings of sample location selected in this study, to enable comparative analysis. The sample data accompany graphical analysis. The other samples were from the WCTP license block, Jubilee oil field area, which also forms part of the study location. The EIA EBS carried out was conducted by TDI-Brooks International aboard R/V JW Powell between 09th through to the 13th of September 2008. The study at this point does consider graphical representation in Figure 10 which represents hydrographical data collected over the TEN and Jubilee fields at varying points in time.

The two graphs of TEN-EBS Station-4 and Jub-EBS0003 attempts to illustrate the relationship between Salinity, temperature and oxygen of the sampled location. (See supplementary material for tabular recorded data).

The graphs (in Figure 10), represent parameter data obtained at varying timelines, thus, EBS Station -4 on the 26th march 2011 and sample station EBS003 on the 12th of June 2008 - marking a three-year interval of data timelines. Both locations fell within a 1400 and 1500 meter water depth zone. Sea temperatures observed varied between $24.80 \mathrm{C}$ to $4.20 \mathrm{C}$ (at Jub EBS 003) and 21.050 C to 4.150 C (EBS Station 4) respectively - and in both cases decreasing along with the water depth. Juxtaposing the above graphs (Figure 10) of March 2011 and June 2008 site data recordings to Figure 11, which are sample analysis graphically produced based on 2020 data gathered on-site study, the assertions in the proceeding paragraphs can be made. Thus, the real sense or level of variations can be determined.

The Jubilee P1 Manifold location (Figure 11 on the right: data taking within February 2020) had a maximum water depth range of 1235 meters (with a median water-depth of 621.5, and standard error (S.E.) of 10.12011199), from which various hydrographical data was as obtained. At a minimum of 8meter water depth, sea surface temperature (SST) was 29.99-degree Celsius (S.E. $=0.147263907$, and a median temp. of 6.31 degree Celsius, Sample Variance $=26.63121632$ ). A minimum temperature of 4.54-degree Celsius recorded was also at the maximum water depths of 1235 meters. Salinity readings also did vary between a maximum and minimum of $35.27 \mathrm{psu}$ and 33.74psu (with a Median = 34.42, S.E. = 0.007588667), whereas max., and min., densities (D) are 33.2522 and $20.8852 \mathrm{~kg} / \mathrm{m} 3$ (with a Standard Error $=0.071268403$, and a Median $=29.75945)$. Dissolved Oxygen (D.O.) estimated over the area showed a median value of $8.934279203 \mathrm{mg} / \mathrm{L}($ S.E. $=0.01663382)$ with a Minimum of $6.267872443 \mathrm{mg} / \mathrm{L}$ and a Maximum of $9.169776741 \mathrm{mg} / \mathrm{L}$ at a $100 \%$ saturation value under $1009.6 \mathrm{mbar}$ of atmospheric pressure.

Similar patterns observed are of the Jubilee FPSO location (see Figure 12) area with a 1002meter water-depth, a minimum temperature of 4.8-degrees Celsius and a maximum of 30.2-degree Celsius

A 34.12psu and 35.39psu as well as 21.0411 and $31.9387 \mathrm{~kg} / \mathrm{m}^{3}$ are the minimum and maximum Salinity, and density values recorded respectively across the water depth- with estimated D.O. ranging between $6.240481615 \mathrm{mg} / \mathrm{L}$ and $9.173744832 \mathrm{mg} / \mathrm{L}$ of $100 \%$ saturation under $1005 \mathrm{mbar}$ of atmospheric pressure.

Additionally, slight variations observed, are in Jubilee-field locations KP0.000 (in Figure 12: data taking in March 2020), and KP48.808 (in Figure 13: data taking in September 2020) over the study period. Again, profiling for chemical and physical parameters in the EIA survey by CSA International, Inc. /TGL, (2011), revealed in total that nitrogen and phosphorous were present in all samples though with minor differences among samples. Differences were also evident in chemical composition for samples collected at deeper depth compared to shallow areas.

Thus, the sample from deeper depth (i.e., at $100 \mathrm{~m}$ or near the bottom) regardless of the sample stations, recorded $<0.24$ to 0.40 and 0.0335 to $0.0545 \mathrm{mg} / \mathrm{L}$ total nitrogen $(\mathrm{N})$ and phosphorous $(\mathrm{P})$ concentrations respectively compared to $<0.15$ to 0.22 and 0.0141 to $0.0161 \mathrm{mg} / \mathrm{L}$ 
of $\mathrm{N}$ and $\mathrm{P}$. Hence, there were no viable differences in chlorophyll and pheophytin concentrations compared to nutrients near the surface and at depth- a subject of productivity and organic mineralisation (CSA International, Inc. /TGL, 2011).

The lack of difference according to CSA International, Inc. /TGL, (2011) suggest the near-surface water column as beset with the same water mass.

Therefore, CSA International, Inc. /TGL, (2011) also stated that, given that the hydrographical parameters were consistent with measured water quality parameters from the various EBS, it was indicative of the general open ocean conditions underpinned by low levels of chlorophyll, suspended solids and nutrients in general. Comparatively, the rest of the selected stations for reanalyses are present in Figure 14 , and Figure 15, which covers surveys conducted in 2008. The data also did concur with the findings of this study in terms of Salinity, DO, Temperature.

The results across 2008, 2011 and 2020 surveys showed very little variation in terms of average sea temperatures, salinity, and density. Thus, considering the thermocline divide by temperature, the halocline divide by salinity levels, and the pycnocline divide by density, according to Fondriest Environmental, Inc., (2013) each of these clines can affect the amount of dissolved oxygen the ocean strata hold. This could in part be attributed to the regions fairly consistent chemical composition across the sea area regardless of the water-depth and composition of the seafloor. Dissolved Oxygen (DO) in the thermoclines regions were higher at 100 per cent saturation. This was not the case for stations with relatively shallow water under 100 meters. The high concentration of DO along the water column of EBS stations with deep-water depth (1000meter above) is in part due to strong offshore wind circulations on the ocean surface. The result also showed that there were no twilight zones (which refers to intercessions) of salinity and temperature samples collected at deep-water enclaves (see Fig. $14,15)$ compared to relatively shallow waters (see Fig. 11,12 , and 13 ), which showed DO levels slightly below $5 \mathrm{mg} / \mathrm{L}$ at relative constant with little variation. Thus though locations with such shallow depth tend to be tidal with fluctuating dissolved oxygen levels where they are near estuaries (Fondriest Environmental, Inc., 2013), the results amplify a region with decline DO- suggesting strong usage by colonies of coastal benthic organisms and pelagic fishes.

The Sound Velocity Gradients: for the sample locations in the 2020 Jubilee study, the researcher also found that the sound velocities showed similar patterns of graduation summarised in Table 1 and Table 2. (See graphs in supplementary material)

Table 1: Sound Velocities computed for three stations between February and March 2020.

\begin{tabular}{|c|c|c|c|c|c|c|}
\hline \multirow[t]{3}{*}{ Descriptive Statistics Terms } & \multicolumn{6}{|c|}{ JUBILEE STATION IDENTIFICATION } \\
\hline & \multicolumn{2}{|c|}{ P1 (10 Feb 2020) } & \multicolumn{2}{|c|}{ B5 (15 Feb 2020) } & \multicolumn{2}{|c|}{ B6 (15 Mar 2020) } \\
\hline & Depth(m) & Velocity(m/s) & Depth(m) & Velocity(m/s) & Depth(m) & Velocity $(\mathrm{m} / \mathrm{s})$ \\
\hline Mean & 505 & 1507.677709 & 505 & 1495.922824 & 493 & 1495.33529 \\
\hline Standard Error & 9.110434 & 0.343496926 & 9.110434 & 0.433606446 & 9 & 0.41149073 \\
\hline Median & 505 & 1504.71 & 505 & 1490.7 & 493 & 1489.38 \\
\hline Mode & $\# N / A$ & 1526.42 & $\# \mathrm{~N} / \mathrm{A}$ & 1485.37 & $\# N / A$ & 1485.13 \\
\hline Standard Deviation & 287.3761 & 10.83513671 & 287.3761 & 13.67751722 & 280.4479 & 12.8224105 \\
\hline Sample Variance & 82585 & 117.4001875 & 82585 & 187.0744774 & 78651 & 164.41421 \\
\hline Kurtosis & -1.2 & -0.368146391 & -1.2 & 1.464434072 & -1.2 & 1.52001305 \\
\hline Skewness & $8.95 \mathrm{E}-19$ & 0.805357118 & $8.95 \mathrm{E}-19$ & 1.377590478 & $-6.2 \mathrm{E}-17$ & 1.42319639 \\
\hline Range & 994 & 39.77 & 994 & 61.23 & 970 & 58.36 \\
\hline Minimum & 8 & 1494.97 & 8 & 1484.01 & 8 & 1484.84 \\
\hline Maximum & 1002 & 1534.74 & 1002 & 1545.24 & 978 & 1543.2 \\
\hline Sum & 502475 & 1500139.32 & 502475 & 1488443.21 & 478703 & 1451970.57 \\
\hline Count & 995 & 995 & 995 & 995 & 971 & 971 \\
\hline
\end{tabular}

Table 2: Sound Velocities computed for two stations in September 2020. 


\begin{tabular}{|c|c|c|c|c|}
\hline \multirow[t]{3}{*}{ Descriptive Statistics Terms } & \multicolumn{4}{|c|}{ JUBILEE STATION IDENTIFICATION } \\
\hline & \multicolumn{2}{|c|}{ Station B2 (05 Sep 2020) } & \multicolumn{2}{|c|}{ Station BX (22 Sep 2020) } \\
\hline & Depth(m) & Velocity(m/s) & Depth(m) & Velocity $(\mathrm{m} / \mathrm{s})$ \\
\hline Mean & 377 & 1498.476762 & 360.5 & 1509.539088 \\
\hline Standard Error & 7.46101 & 0.409135915 & 7.653975 & 0.264031256 \\
\hline Median & 377 & 1495.25 & 360.5 & 1508.67 \\
\hline Mode & $\# \mathrm{~N} / \mathrm{A}$ & 1486.94 & $\# \mathrm{~N} / \mathrm{A}$ & 1521.39 \\
\hline Standard Deviation & 192.6906 & 10.56648452 & 202.7942 & 6.995582733 \\
\hline Sample Variance & 37129.67 & 111.6505952 & 41125.5 & 48.93817777 \\
\hline Kurtosis & -1.2 & -1.274934095 & -1.2 & -1.33726051 \\
\hline Skewness & $-6 \mathrm{E}-17$ & 0.490753374 & $-4.1 \mathrm{E}-17$ & 0.168369103 \\
\hline Range & 666 & 31.85 & 701 & 22.3 \\
\hline Minimum & 44 & 1486.68 & 10 & 1499.09 \\
\hline Maximum & 710 & 1518.53 & 711 & 1521.39 \\
\hline Sum & 251459 & 999484 & 253071 & 1059696.44 \\
\hline Count & 667 & 667 & 702 & 702 \\
\hline
\end{tabular}

The study found the median sound velocity range of $1489.38 \mathrm{~m} / \mathrm{s}$ and $1508.67 \mathrm{~m} / \mathrm{s}$ over varying water depths ranging from 8 meters to 1002 meter depth of the various sample locations. The findings are in agreement with previous data which categorises sound velocity at $1500 \mathrm{~m} / \mathrm{s}$ - allowing animals using sound to detect target prey (during echolocation), achieved their goal with wavelength 4 or 5 times to length of target prey (Project Oceanography, 2000). It is also useful in animal navigations, feeding and breeding.

\subsubsection{Habitat Found in the Region and Vulnerability Concerns}

The nature of the habitat observed was based on animal sightings that took place throughout the study. This period refers to the January to March 2020, and the September 2020 field observations. Other observations of species made include the periods of March 2017 to March 2018 on the offshore Sankofa Gye Nyame oil and gas field; and September to November 2015 on the TEN oil and gas fields. Among some of the animals observed, interest includes pelagic fishes, sharks, Short-finned Pilot whales, Bottlenose Dolphins, Humpback Whales, Marine Turtle, and Mantra. Bottom dwellers also observed included worms and pink coloured jellyfishes at locations as deep as 700meters on the Sankofa Gye Nyame field. Again, observation of offshore subsea construction operations over the period did appear to have risk implications in terms of sound (underwater noises), movement, night-time lightings, flaring and pollution. Several sightings of Mantra like that seen in Figure 16 occurred at over 100meter water depth which corresponded with the high levels of dissolved oxygen concentrations.

Table 3 here list some of the essential animals observed. Seabirds were a continuous presence through the period of September on feed hunting routs.

Table 3: Some Frequently Observed Animals 


\begin{tabular}{|ll|}
\hline Month of Observation & Animals Sighted \\
\hline January & Bottlenose Dolphins \\
\hline January, February, March, September & Short-finned Pilot Whales \\
\hline February & unidentified cetacean \\
\hline September & Seagull \\
\hline February, September & Mantra \\
\hline March September & Marine Turtle \\
\hline June, July, August & unidentified dolphins \\
\hline February & Sharks \\
\hline All months during the survey & Variety of Fishes \\
\hline
\end{tabular}

Source: field survey

Given that the area lies directly in the heart of the West African shipping lane as depicted in Figure 17

(http://www.nceas.ucsb.edu/GlobalMarine/impacts, 2009; ERM, 2009), there are real vulnerabilities if measures are not adequately designed to cater for the growing changes. Other vulnerabilities identified were the concern of marine plastic particularly along the coast and oil spill (Lamptey and Sackey, 2017).

[1] Squall is a sudden violent gust of wind or localized storm, especially one bringing rain, snow, or sleet.

\section{Conclusions}

The region under the study appeared to have rich biodiversity - fostering the presence of various marine animals clustered along with the various web of the food chain. The tropical nature of the region meant high radiation influx from the sun- leading to the thermal insulation of the Area. The dynamic also is critical to the ocean and atmospheric relationship - thus, driving both wind and ocean current circulations. Winds observed were within southwestern quadrants (Fig. 3 and 4), similar to ocean surface currents (Fig. 9). The atmospheric temperature (Fig. 7) recordings taking were a direct function of the solar energy absorbed into the atmosphere, delimiting humidity infrared wave outputs. The ocean sampled showed consistency with underlining EBS studies. Thus, from all the locations sampled in this study with results in Fig. 11, 12, 13 and 14 density remained relatively constant and in agreement with Boussinesq Approximation (Bastiaan Willink (2008); Joseph Boussinesq, 1842-1929) principles and assumptions, except where gravity was of concern. In this case, the study looks into marine animals' navigations and marine assets movement within water columns of the offshore marine environment. Sea temperatures also showed a pattern of declination along with the water depth (pressure) from the ocean surface to the bottom (seafloor). Variation in salinity in some cases was relatively small. These two conditions have a direct impact on sound travel in the ocean, though the latter (salinity recordings) in this case is negligible. The velocity at which sound travels in the ocean environment is primary to the marine animals' interactions of the region (NOAA, (2016 pp63-64); Stewart, 2008). This velocity was also imperative in understanding the adverse effect of the anthropogenic noises generated by marine assets. Sound velocity from the study region recorded is found in Table 1 and 2. According to Stewart (2008), in typical ocean conditions, project speed within the range of $1450 \mathrm{~m} / \mathrm{s}$ to $1550 \mathrm{~m} / \mathrm{s}$. The study's findings of $1493.5 \mathrm{~m} / \mathrm{s}$ and $1534.74 \mathrm{~m} / \mathrm{s}$ for station P1 (Jubilee P1 Manifold) Location (in Fig 11) agree with this typical ocean speed limits determined.

Another ocean condition that delineates the habitable nature of the offshore region was the amount of dissolved oxygen mix along the water column. Dissolved oxygen is a necessity to many lifeforms, and that includes fish, invertebrates, bacteria and plants (Fondriest Environmental, Inc., 2013). Fondriest Environmental, Inc., (2013) reiterated that organisms within the marine environment use this oxygen for respiration; thus, in similar ways to living organisms found on land. They described the respiration process in fish and crustaceans as one that occurred through the use of gills. They also emphasised that dissolved oxygen for respiration only took place in plant life and phytoplankton, during periods of unavailable sunlight for photosynthesis - and thus, suggesting the amount of dissolved oxygen needed by organisms varied. This assertion is true as the samples from the study showed D.O. levels relatively lower near sea surface compared to the ocean bottom dwellers. The dissolved oxygen structure along with the water depth also did suggest the nature of habitat stratification at each location - with regions of less D.O. indicating areas of dense marine habitats. In other words, more animals inhabited are near the ocean surface at most times and may subject them to anthropogenic stressors (Parker et al., 1999) that compound largely at the nearsurface column. Fondriest Environmental, Inc., (2013) cites organisms (sea bottom feeders) such as crabs, oysters and worms as those requiring minimal oxygen of 1-6 mg/L, compared to shallow water fish - requiring higher levels of 4-15 mg/L (Osmond, D. L. et al, 1995).

Page $10 / 23$ 
Therefore, marine mammals of the order Odoncetes such as pilot whales, bottlenose dolphins, and predator fish like sharks sighted, suggest the offshore area as a conducive feeding ground all year-round. The above discussed adds to the essential news of the recent discovery of coral reefs in the region that has triggered the interest of scientist. The underlining condition of the larger marine environment of the Gulf of Guinea area as favourable habitation for living mammals require further studies. Recent events suggest the need to ensure the area protected along with the increasing anthropogenic activities in the region. Thus, there is the eminent danger with growing marine traffic routed in the area (see Fig 17).

\section{Declarations}

\section{Acknowledgements, Samples, and Data}

Our most excellent acknowledgement goes to family and friends who supported us through this study in diverse ways. We wish to thank the Subsea Seven Borealis Team, who contributed to this study with their enormous experience and thoughtfulness. Our final thanks go to Prof Fava of the Selinus University of Science and Literature.

\section{Conflict of interest}

Regardless of lead authors working relations with Subsea 7 Borealis vessel management, and having access to vessel equipment and documents, on behalf of all authors, the lead author wishes to state that at no stage in this study did the concerns of conflict cloud our judgement.

\section{References}

Bastiaan Willink (2008). The Collaboration between Korteweg and De Vries | an Enquiry into Personalities.

https://www.researchgate.net/publication/268711688_The_collaboration_of_Korteweg_and_de_Vries_on_the_trail_of_personalities/figures? $\mathrm{lo}=1$

Benson, B.B., and Daniel Krause, Jr, (1980). The concentration and isotopic fractionation of gases dissolved in freshwater in equilibrium with the atmosphere. 1. Oxygen: Limnology and Oceanography, vol. 25, no. 4, p. 662-671. Retrieved from; http://www.jstor.org/stable/pdfplus/2835754.pdf.

Benson, B.B., and Daniel Krause, Jr, 1984, The Concentration and Isotopic fractionation of oxygen dissolved in freshwater and seawater in equilibrium with the atmosphere: Limnology and Oceanography, vol. 29, no. 3, p. 620-632. Retrieved from; http://www.jstor.org/stable/pdfplus/2836308.pdf.

Brown R. B. P., and Brown N., (2016). Brown's Nautical Almanac. Brown, Sons \& Ferguson Ltd. Glasgow, UK.

CSA International, Inc. /TGL (2011). Introduction. https://www.tullowoil.com/download_file/view/601/

Cullen, J.J., Neale, P.J., and Lesser, M.P. (1992) Biological weighing function for the inhibition of phytoplankton photosynthesis by ultraviolet radiation. Science (New York, N.Y.), 258(5082), 646-650. Retrieved from; https://doi.org/10.1126/science.258.5082.646

Environmental Resource Management and Tullow Ghana Limited, ERM/TGL, (2014). Tweneboa, Enyenra, Ntomme (TEN) Project, Ghana: Final Environmental Impact Statement. Volume II, Doc no: 00002-E78-ES-RPT-0007 - REV 1

Environmental Resource Management and Tullow Ghana Limited, ERM-TGL (2009). Environmental and Socio-economic Baseline. Retrieved from; https://www.tullowoil.com/application/files/7615/8491/9054/jubilee-field-eia-chapter-4-pt1.pdf

ESL Consulting/ENI S.p.A (2015). Eni for 2015 - Our sustainability report. https://www.eni.com/assets/documents/documentsen/eni_for_2015_report_eng_.pdf

Fondriest Environmental, Inc., (2013). The Dissolved Oxygen Handbook: A Practical Guide to Dissolved Oxygen Measurements. Retrieved from; https://www.fondriest.com/pdf/ysi_do_handbook.pdf

GCNS GCM (2009). Ocean Current Circulations. http://www.coastalwiki.org/wiki/Ocean_circulation

Ghana National Chamber of Commerce and Industry, GNCCI (2017). Situational Analyses of the Ports in Ghana - GNCCI Finale. Retrieved from; https://www.ghanachamber.org/index.php/downloads/category/6-research-articles?download=44:situational-analyses-of-the-ports-

Page $11 / 23$ 
in-ghana-gncci-finale

Ghana National Gas, GNG, (2021). Operations. Homepage. https://www.ghanagas.com.gh/operations

Global Construction Review, GCR (2017). GCR Media Pack.

https://www.globalconstructionreview.com/client_media/pdfcontent/CIOB_MEDIA_2017_GCR.pdf

Huang R.X., (2015) Oceanographic Topics | Surface/Wind-Driven Circulation. Encyclopedia of Atmospheric Sciences (Second Edition), pp301-314. Retrieved from; https://doi.org/10.1016/B978-0-12-382225-3.00280-2

GEO ExPro (2019). Activity Map of offshore Ghana. In: First Independent Hydrocarbon Discovery in Ghana.

https://www.geoexpro.com/articles/2019/12/first-independent-hydrocarbon-discovery-in-ghana

Koranteng K., (2017). WHO IS KILLING THE WHALES IN GHANA? Crusading Guide News Article. Retrieved from;

https://www.linkedin.com/pulse/who-killing-whales-ghana-kwabena-koranteng/?trackingld=9Qf\%2BjVFIR8aH\%2Bt5S\%2B8BfJQ\%3D\%3D

Lamptey B. L., and Sackey A. D., (2017). The Need to Subscribe to Satellite Detection and Monitoring For Sea-Based Oil Spillage in Ghana. Regional Maritime University Journal

Mackenzie, K.V. (1981). Nine-term Equation for Sound Speed in the Oceans. 70; 807-812, Journal of Acoustic Society, USA.

Mitchell F., (2020). Ghana's Maritime Future. Online Article. http://africalive.net/article/ghanas-maritime-future/

National Geographic Society, NGS (2020). Human Impacts on the Environment. https://www.nationalgeographic.org/topics/resourcelibrary-human-impacts-environment/?q=\&page=1\&per_page=25

NOAA Ocean Noise Roadmap (ONR) (2016). Ocean Noise Strategy Roadmap. https://cetsound.noaa.gov/road-map

NOAA, data. http://www.ngdc.noaa.gov/mgg/sedthick/sedthick.html

Osmond, D.L., D.E. Line, J.A. Gale, R.W. Gannon, C.B. Knott, K.A. Bartenhagen, M.H. Turner, S.W. Coffey, J. Spooner, J. Wells, J.C. Walker, L.L. Hargrove, M.A. Foster, P.D. Robillard, and D.W. Lehning. (1995)

Parker E. D., Forbes Jr., V. E., Nielsen S. L., Ritter C., Barata C., Baird D. J., Admiraal W., Levin L., Loeschke V., Lyytikäinen-Saarenmaa P., HøghJensen H., Calow P. and Ripley B. J., (1999 pp. 179-184 (6 pages)) Stress in Ecological Systems

Plastic Punch Ghana, (2020). Ocean Cleaning and Recycling. Retrieved from; https://www.seaqual.org/projects/plastic-punch

Project Oceanography (2000). Unit 2. Lesson 3. Sound Use by Marine Mammals.

https://www.marine.usf.edu/pjocean/packets/f00/f00u2le3.pdf

Radtke D.B., White A.F., Davis J.V., and Wilde F.D., (1998). 6.2 Dissolved Oxygen. Retrieved from; https://pubs.usgs.gov/twri/twri9a6/twri9a62/twri9a6_Section6.2.pdf

Richard B. P. Brown (Ed) and Nigel Brown, (2016) Brown's Nautical Almanac (2016). Admiralty Charts and Publications, Brown, Son and Ferguson Limited, Glasgow Great Britain

Rui Xin Huang (2017). Reference Module in Earth Systems and Environmental Sciences. In: Mohite-Patil T. B., Saran A. K., Sawant S. R., Chile R. H., Mohite-Patil T. T., (2010). Simulation Study of Acoustic Wave Propagation in Ocean. Retrieved from; https://www.ijcaonline.org/volume12/number8/pxc3872132.pdf

Stewart R. H., (2008) Introduction to Physical Oceanography. Texas A \& M University, Department of Oceanography, USA. https://www.uv.es/hegigui/Kasper/por\%20Robert\%20H\%20Stewart.pdf

The Lakes Environmental Software Ver 7.0.0., (2018). WRPLOT View - Version 8.0.2 - Freeware Wind Rose Plots for Meteorological Data. 20.6 MB software. Retrieved from; https://www.weblakes.com/products/wrplot/index.html

U.S. Geological Survey (USGS), (2011) Office of Water Quality Technical Memorandum 2011.03: Change to Solubility Equations for Oxygen in Water 
UNESCO (1981).The Practical Salinity Scale 1978 and the International Equation of State of Seawater 1980. UNESCO Technical Papers in Marine Science 36, 25 pp. In: Millero, F.J. 2010. History of the equation of state of seawater. Oceanography 23(3):18-33,

doi:10.5670/oceanog.2010.21. Retrieved from; https://tos.org/oceanography/assets/docs/23-3_millero.pdf

Verdict Media Limited, (2020). WHO declares Covid-19 outbreak a pandemic. https://www.pharmaceutical-technology.com/news/whodeclares-covid-19-pandemic/

Weiss, R.F., (1970). The solubility of nitrogen, oxygen and argon in water and seawater: Deep-Sea Research, vol. 17, p. 721-735. Retrieved from; http://water.usgs.gov/owq/rfweiss.paper.pdf.

\section{Figures}

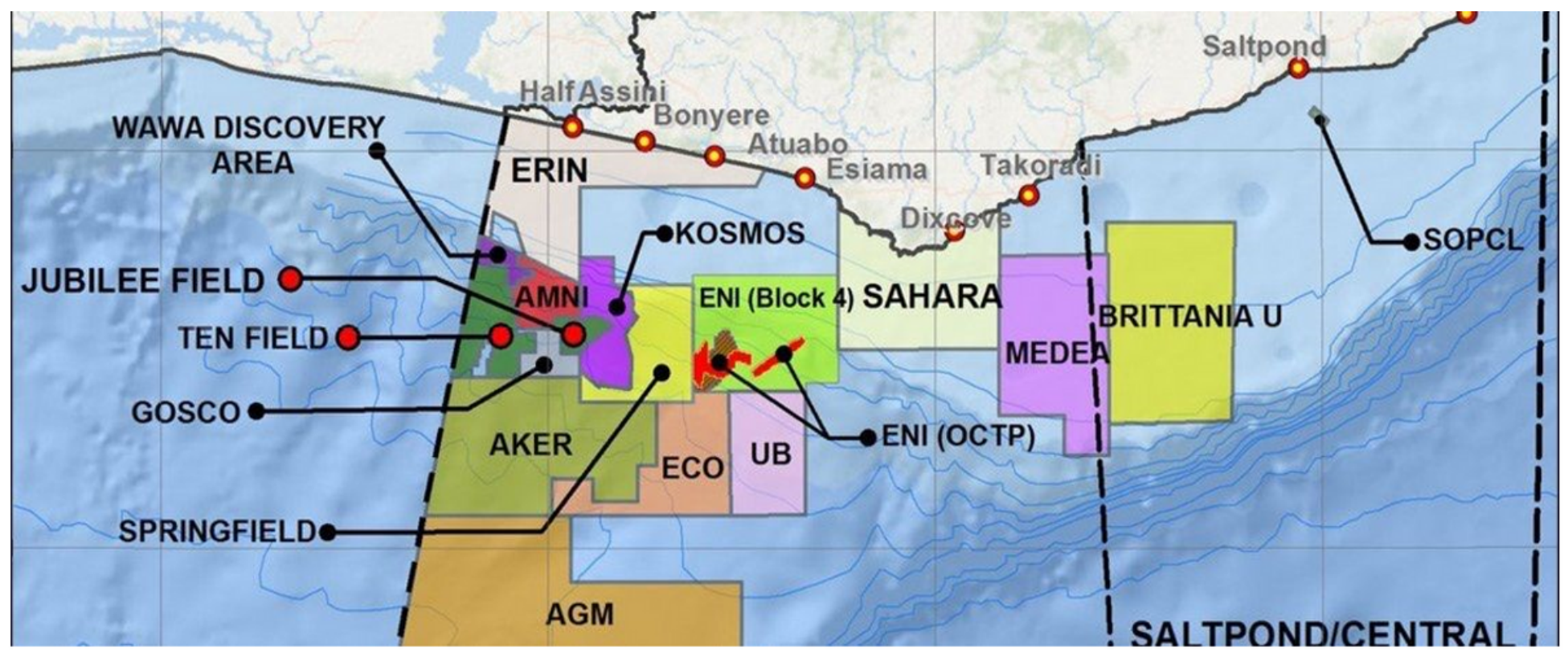

Figure 1

Image offshore hydrocarbon basins of Ghana. The western basin is to the left nearest to Ivory Coast, the eastern basin is bounded to the right nearest to Togo, and the central basin sits right between the western and eastern basins. Courtesy; GEO ExPro (2019). 


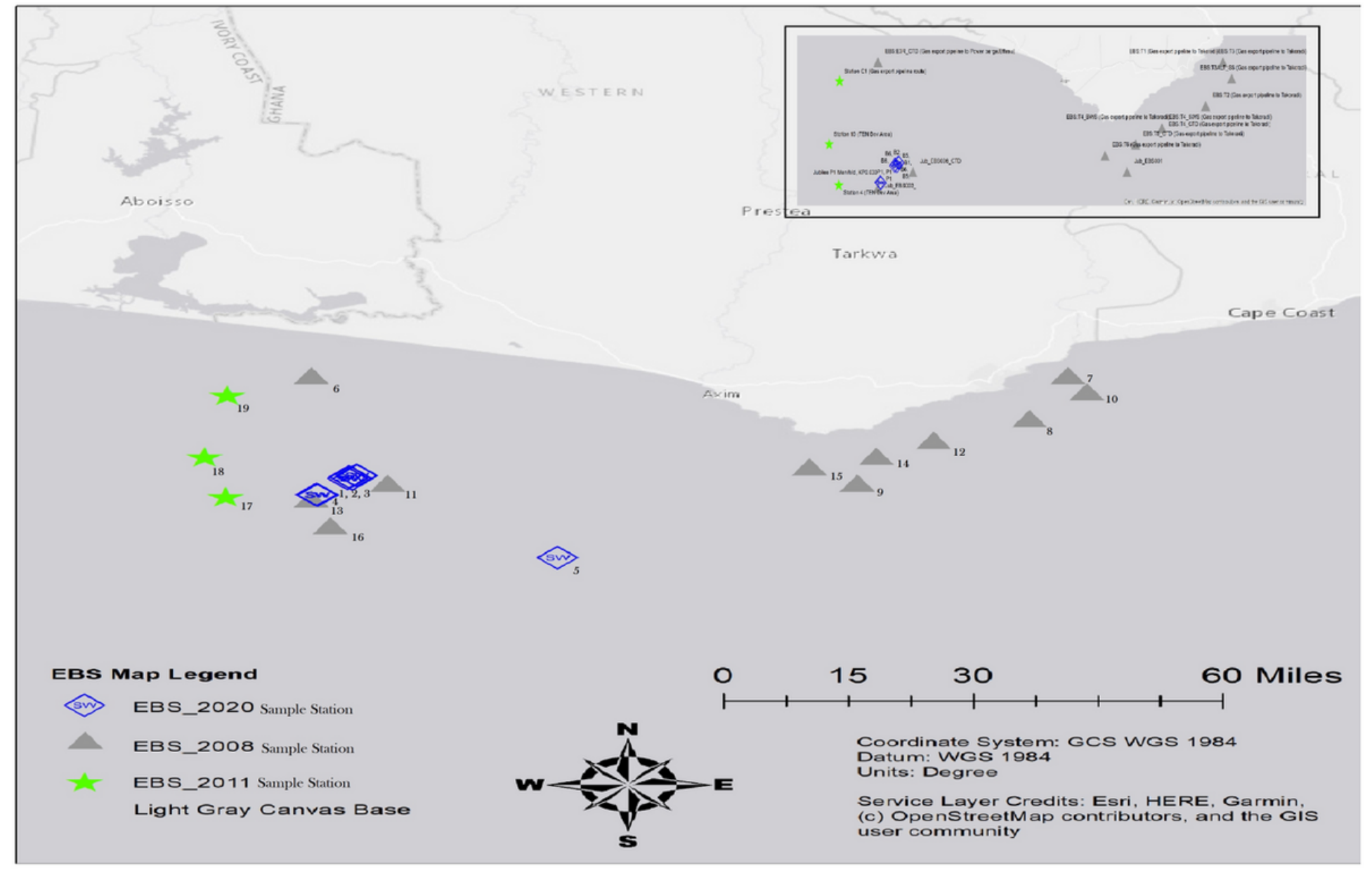

Figure 2

Selected Stations for the environmental baseline data sampling Survey

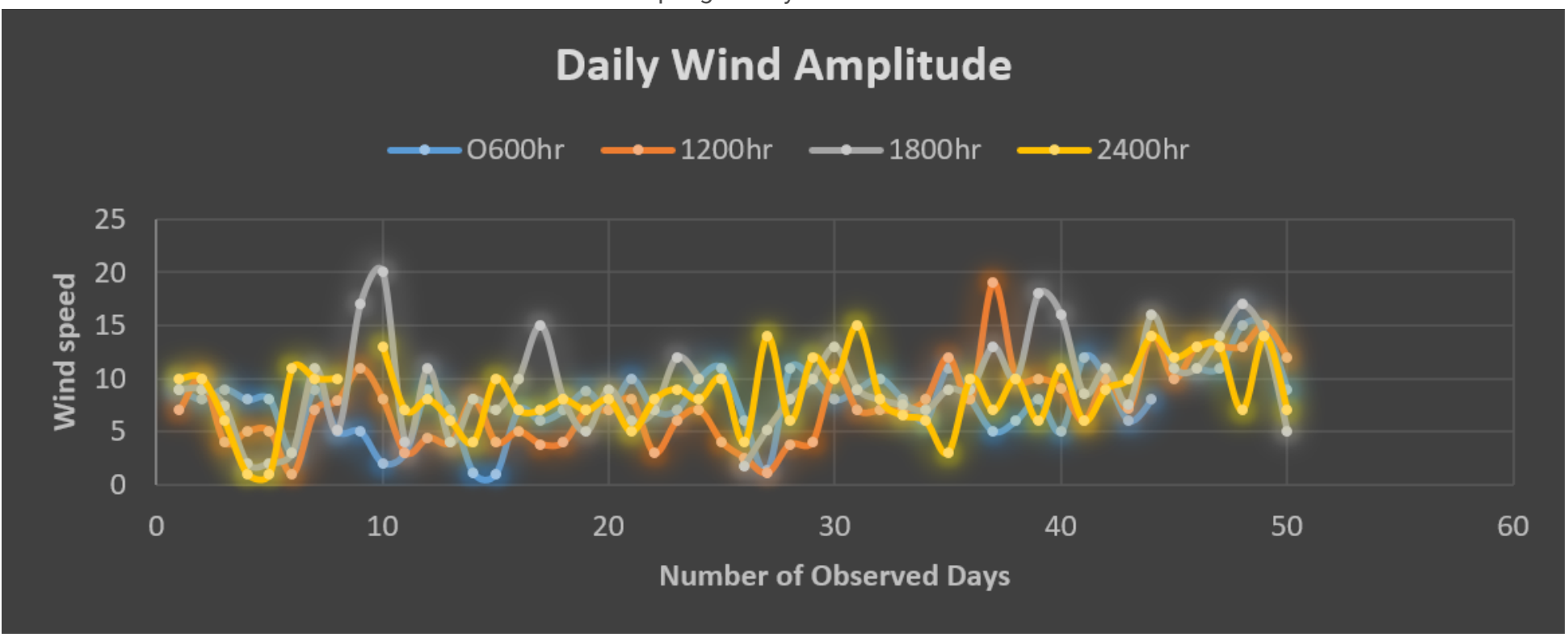

Figure 3

Wind speed over $24 \mathrm{hr}$ period 

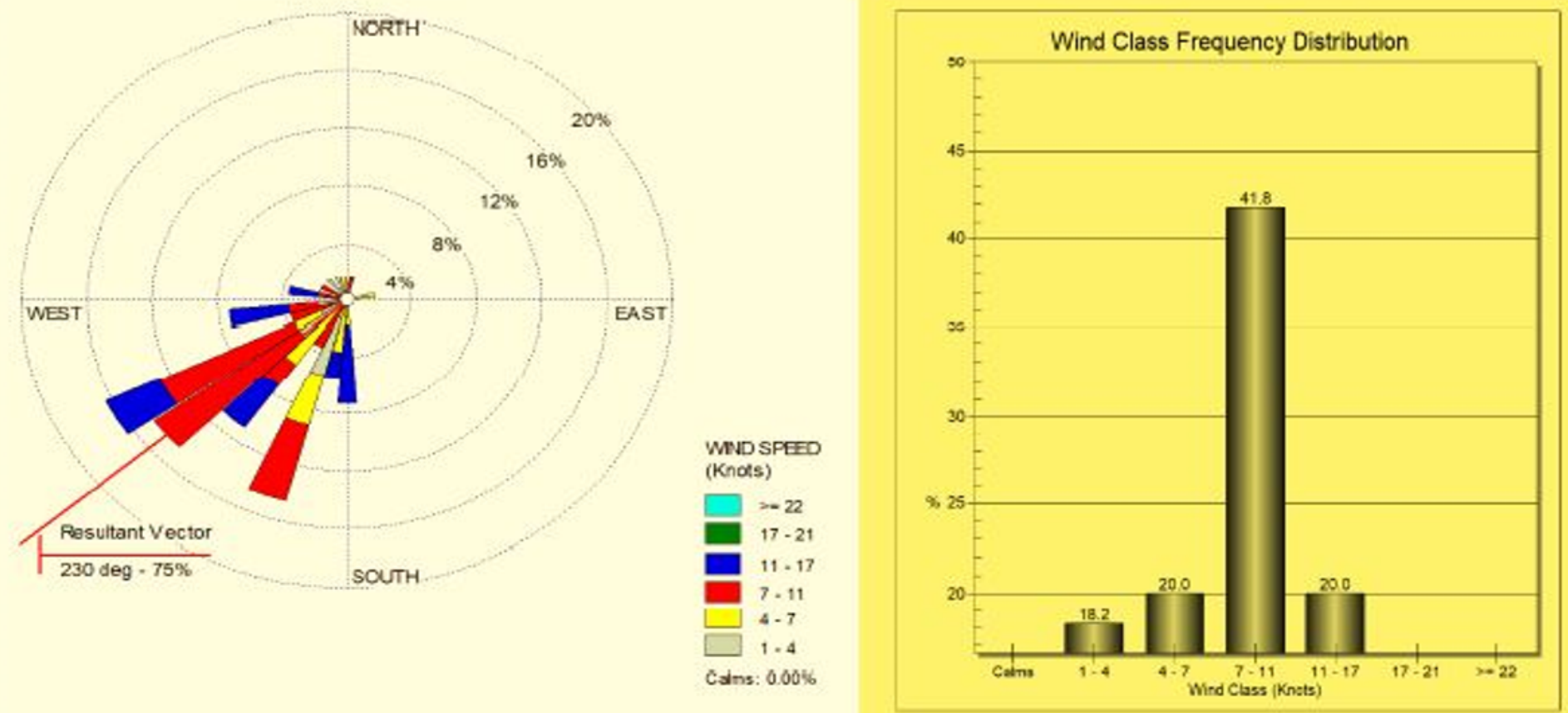

Figure 4

left: Wind Rose and right: Speed Frequency

\section{Daily pressure (Jan- March, 2020)}

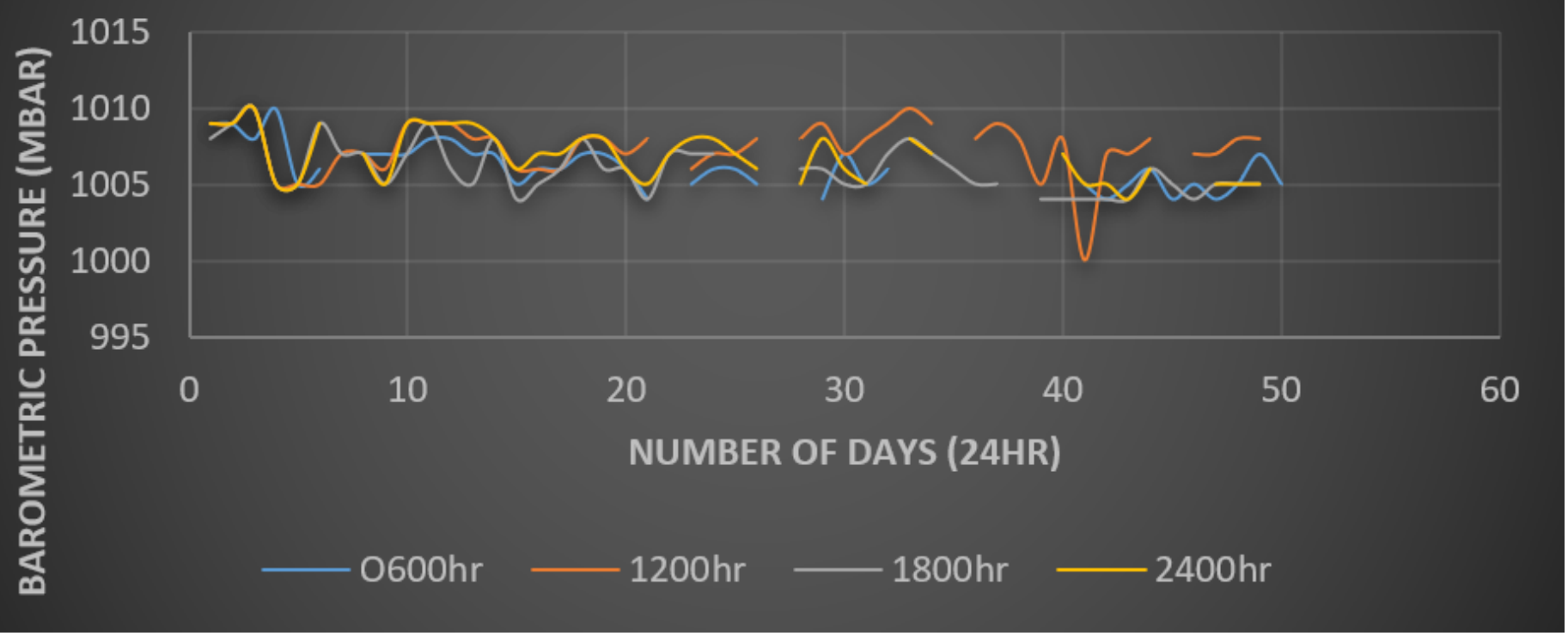

\section{Figure 5}

The 24hr Atmospheric Pressure 

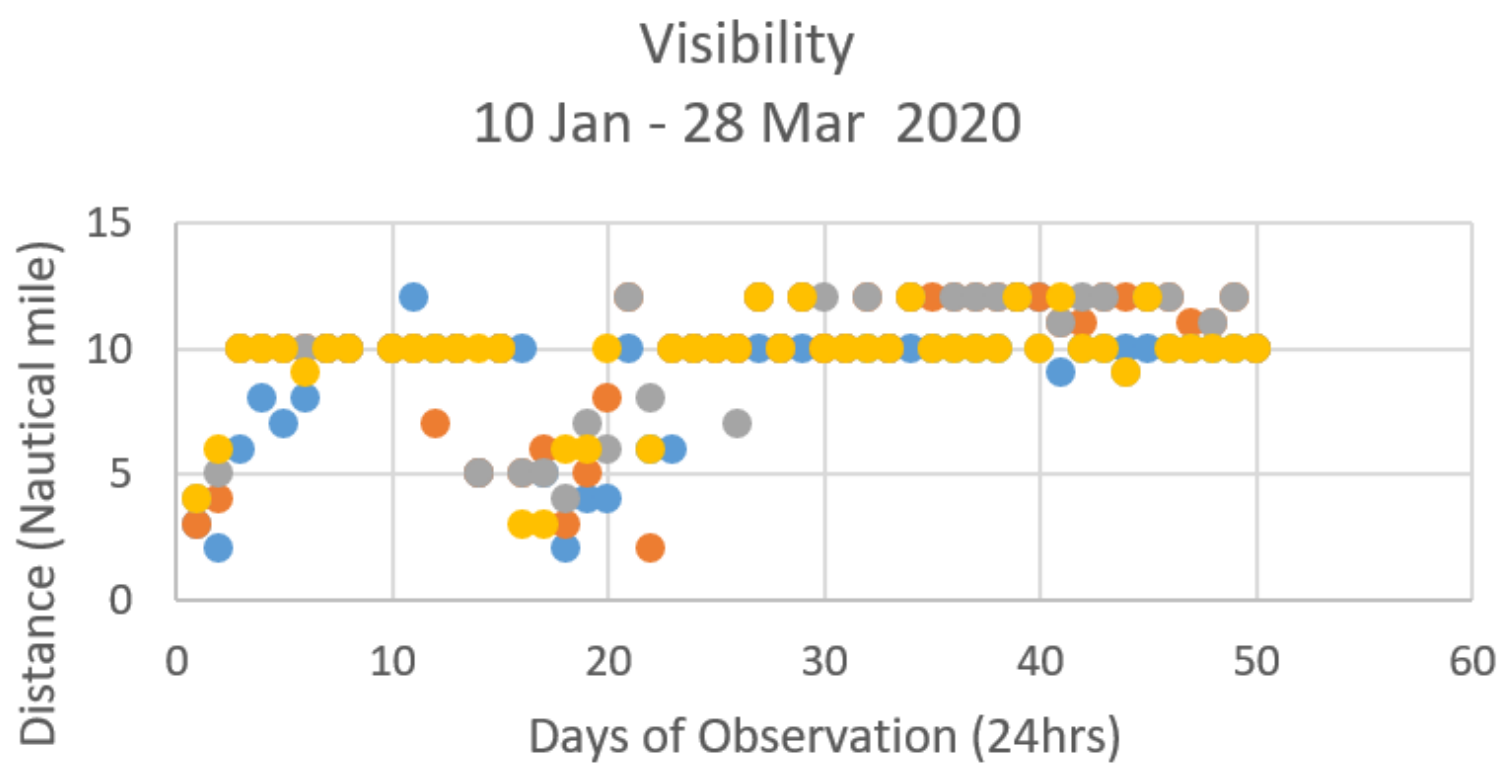

$0600 \mathrm{hr} 1200 \mathrm{hr} 1800 \mathrm{hr} 2400 \mathrm{hr}$

Figure 6

Observed Visibility over $24 \mathrm{hr}$ period

Atmospheric Temperature Jan - Mar 2020

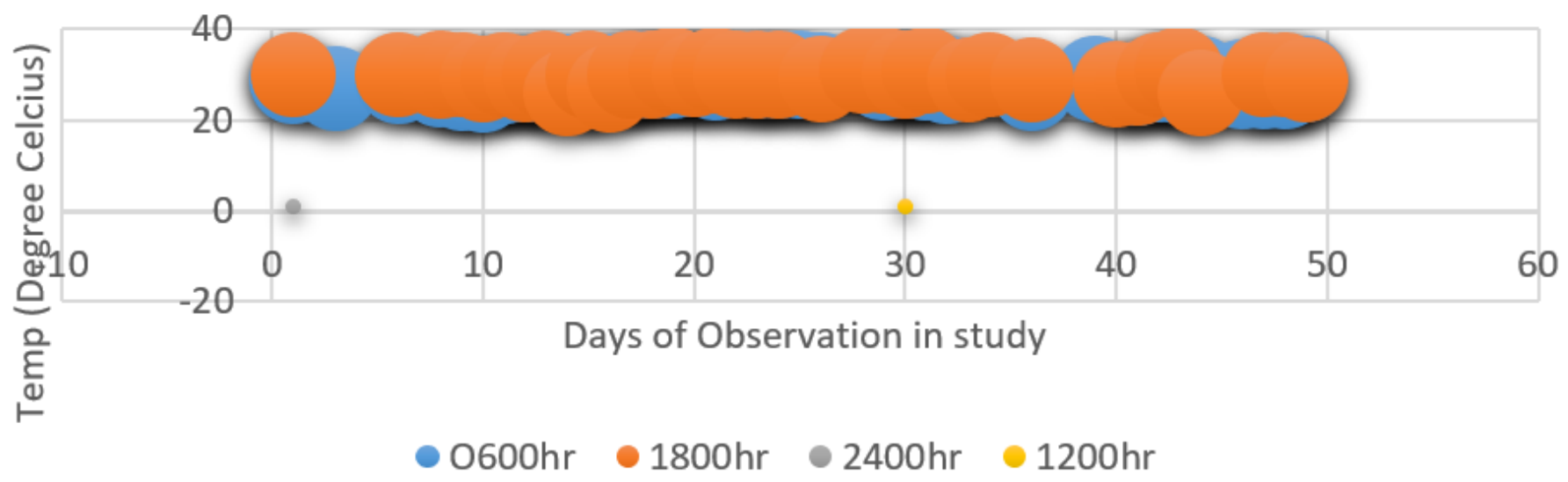

Figure 7

Atmospheric Temperature over 24hr period 
Wave Amplitude (Jan -Mar 2020)

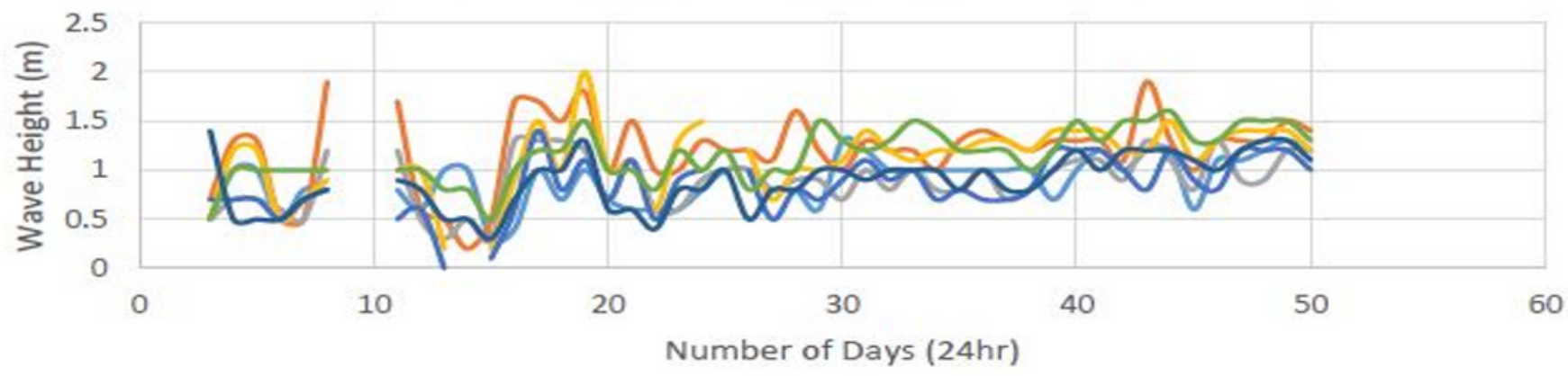

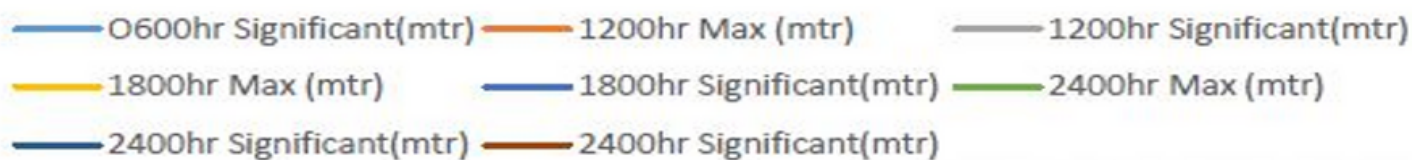

max_wave_height

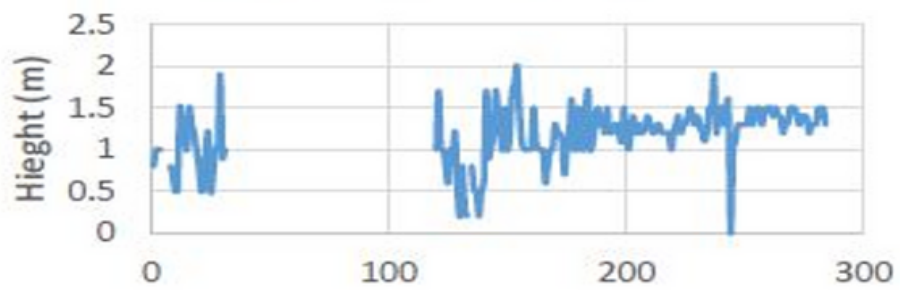

DAY OF RECORDING
WAVE DIRECTION (JAN - MAR 2020)

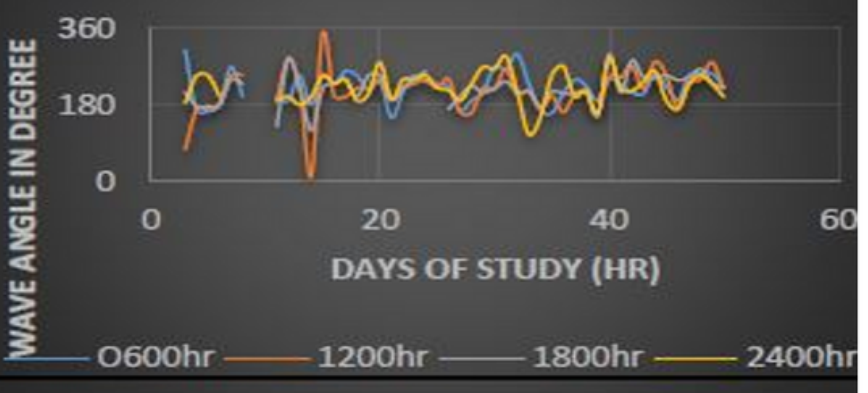

\section{Figure 8}

(a) Significant Wave Amplitudes over 24hr period; (b) Maximum and Minimum Wave Hieghts; (c) Pattern of Wave Direction over 24hr period

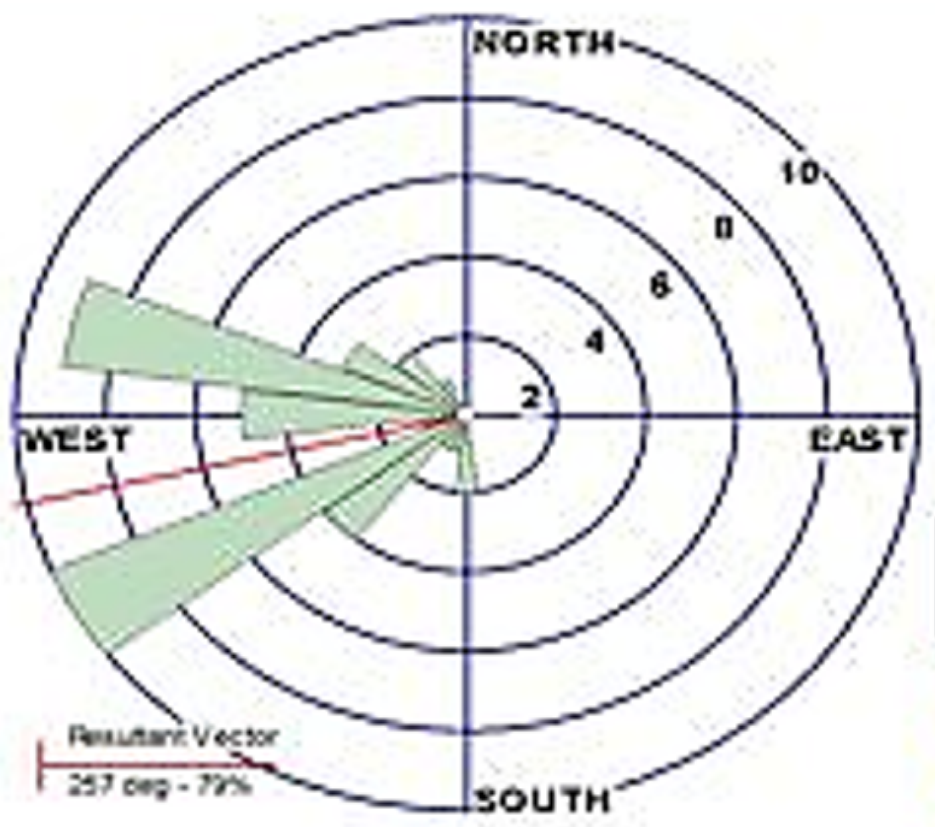

\section{CURRENT}

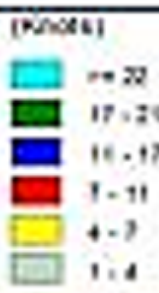


Figure 9

Surface Current speed and direction over 24hr period

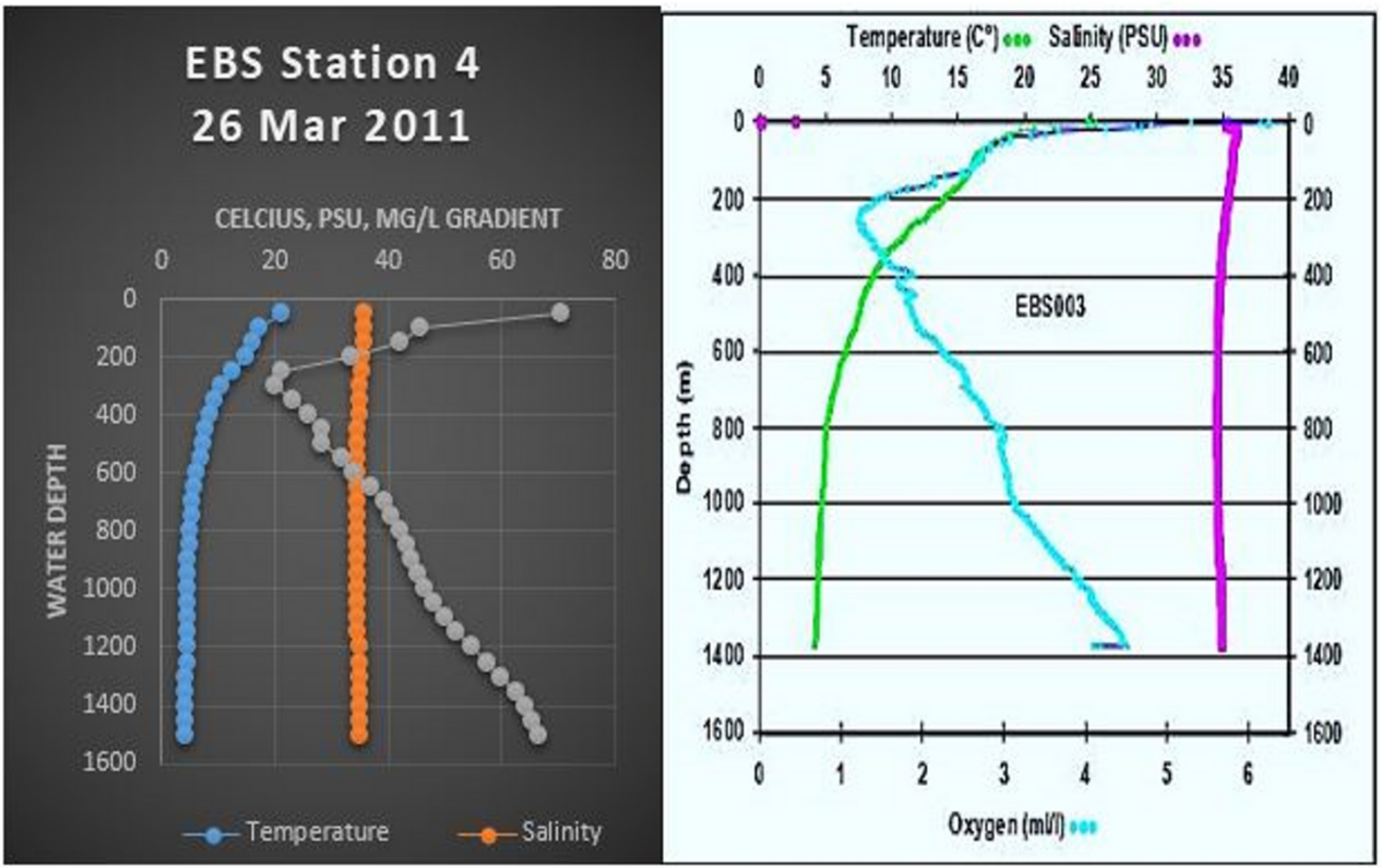

Figure 10

Reanalysis of relationship between Temperature, Salinity and Oxygen over water depth from Profile site EBS 4 (tabular data obtained for TEN field development EIA) and EBS003 (obtained for Jubilee development) for reanalysis. Sourced data obtained from CSA Int. Inc. / TGL (2011) Table 7; and TDI-Brooks/TGL (2008) EIA EBS report respectively

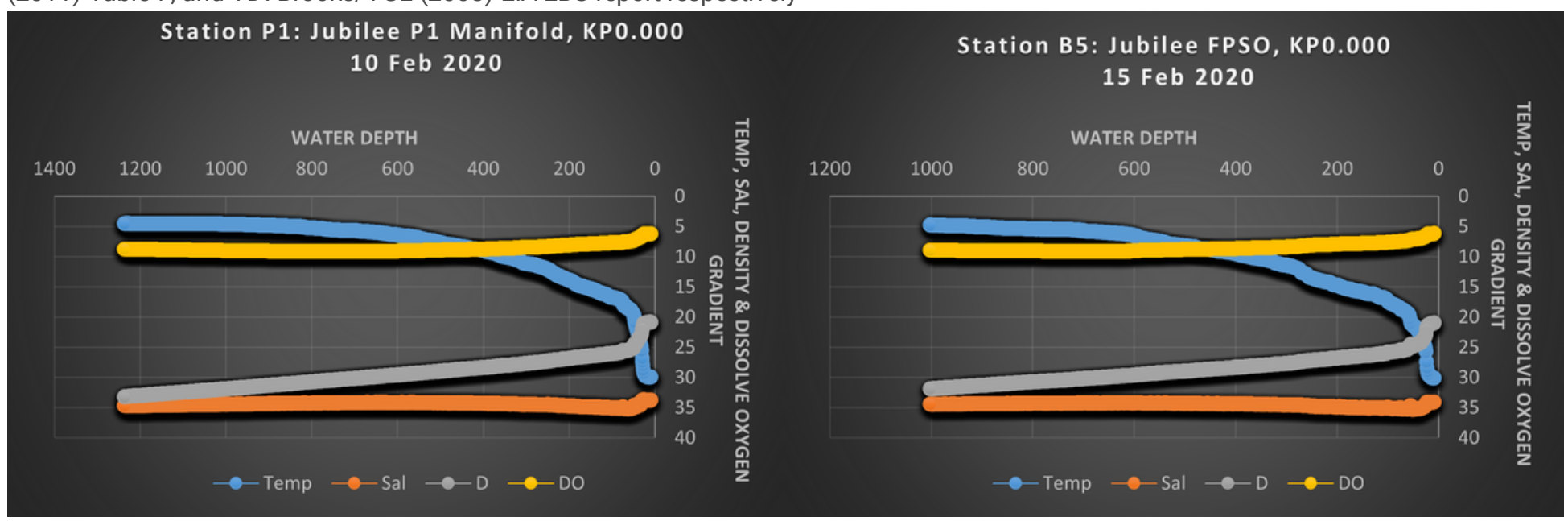

Figure 11

Hydrographic data. Lef: EBS Station- Jubilee P1 Manifold; Right: EBS Station-Jubilee FPSO 


\section{STATION B6: JUBILEE, KP0.000 13 MARCH 2020}

- Temp Sal $\triangle \mathrm{D} \times$ Dissolved Oxygen at $100 \%$ saturation

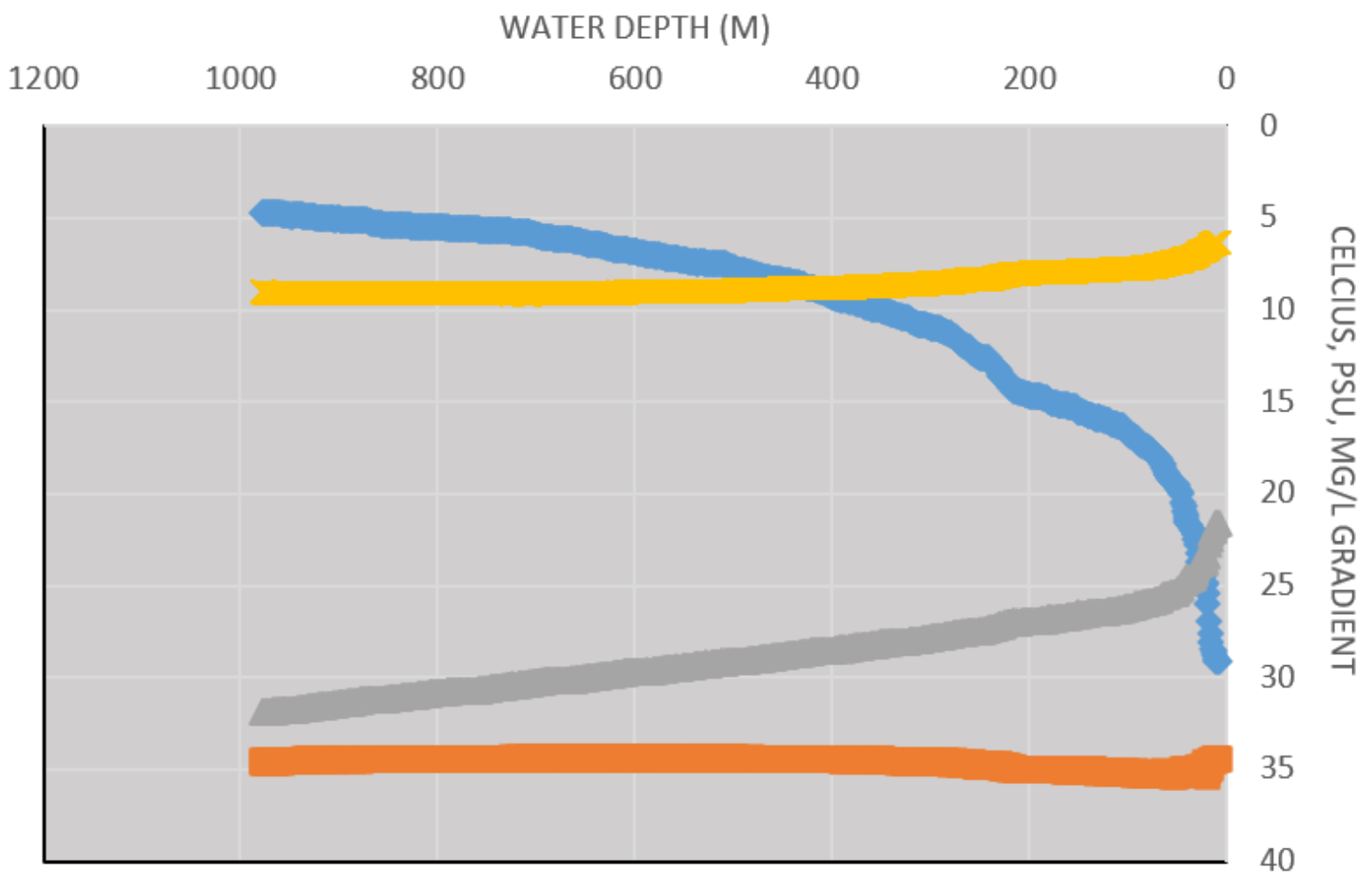

Figure 12

Hydrographic Data for EBS from Jubilee Station 


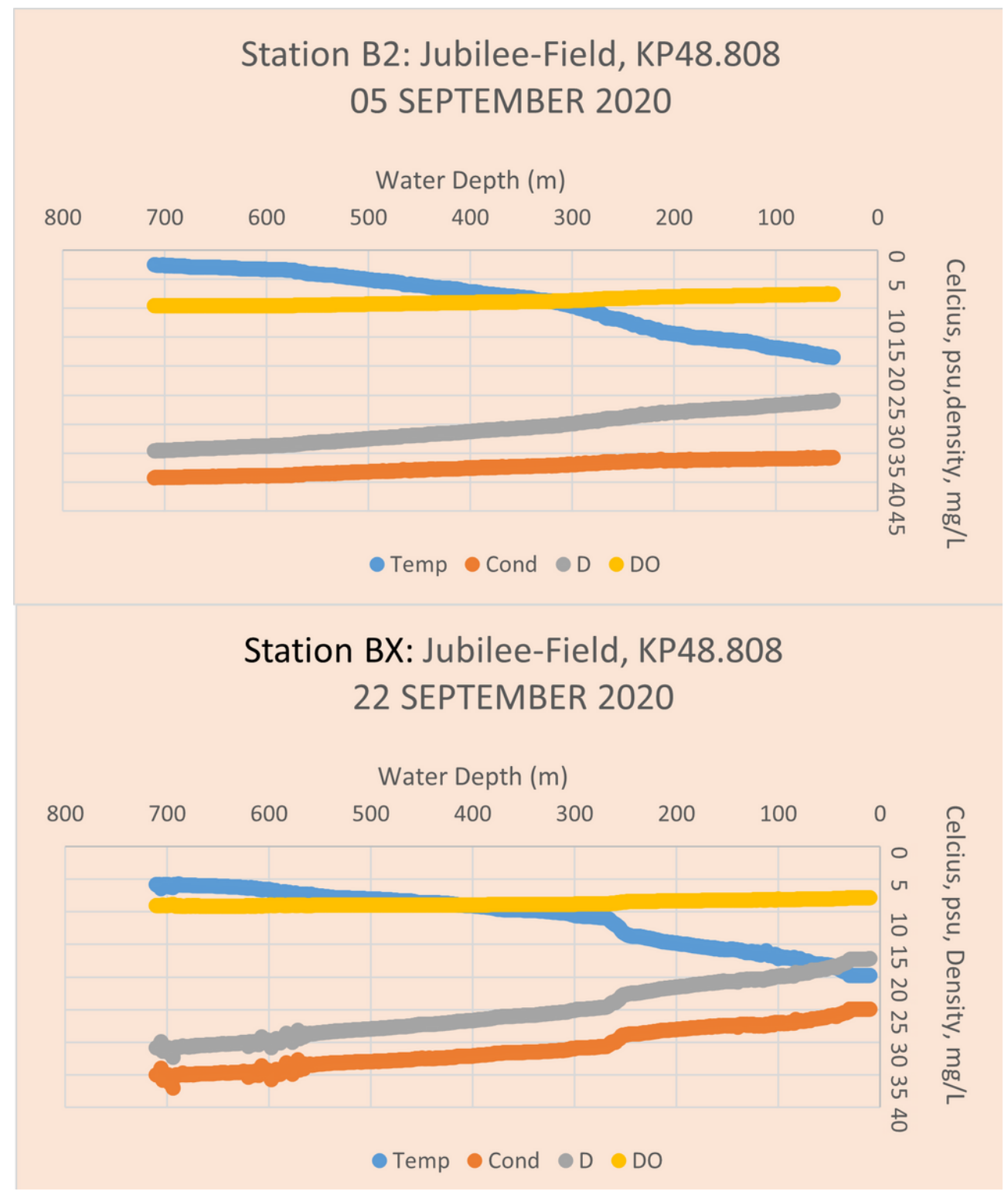

Figure 13

Hydrographic data. EBS Station Jubilee Field KP48. 


\section{EBS STATION E2, 11 Sep 2008}

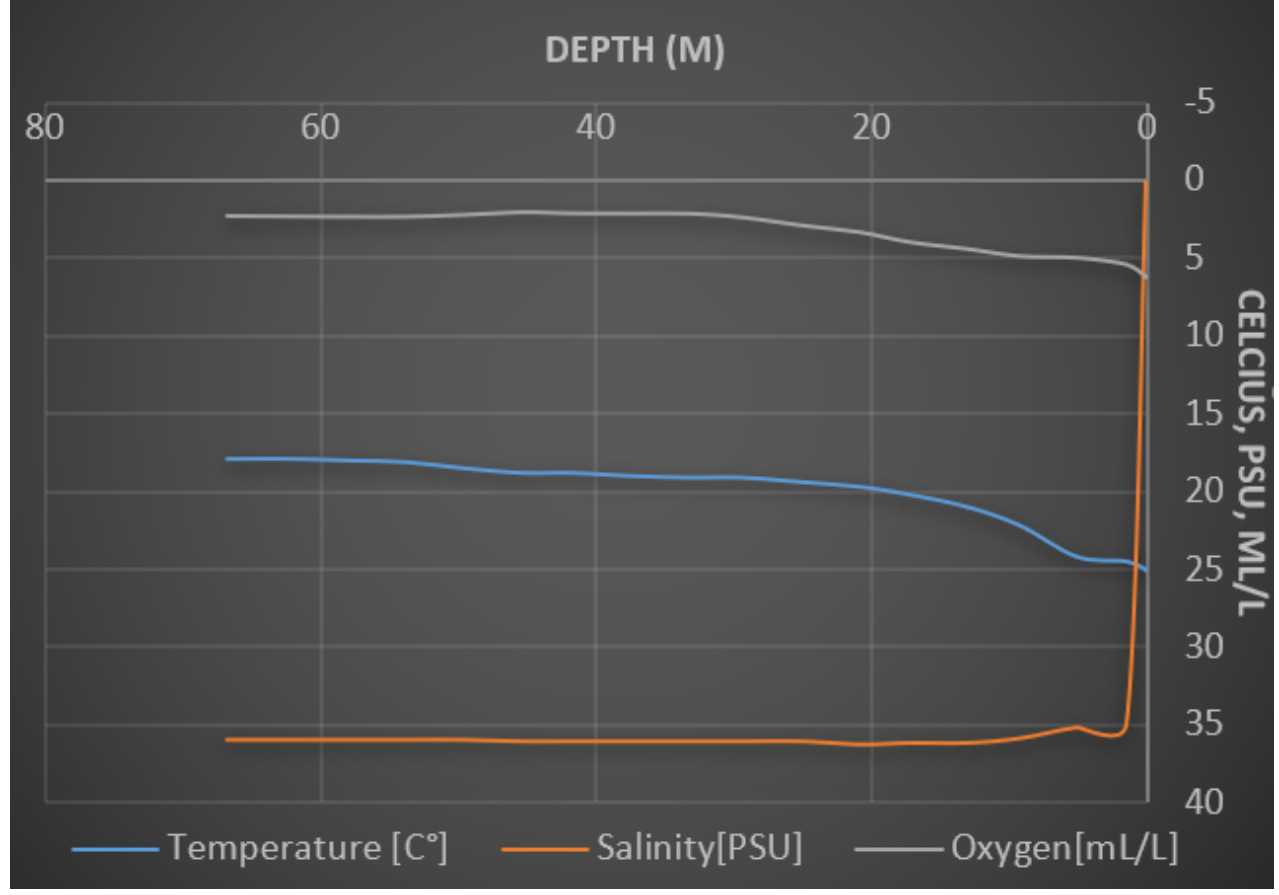

\section{Figure 14}

Hydrographical data from 2008 EBS EIA by ERM/TGL. 


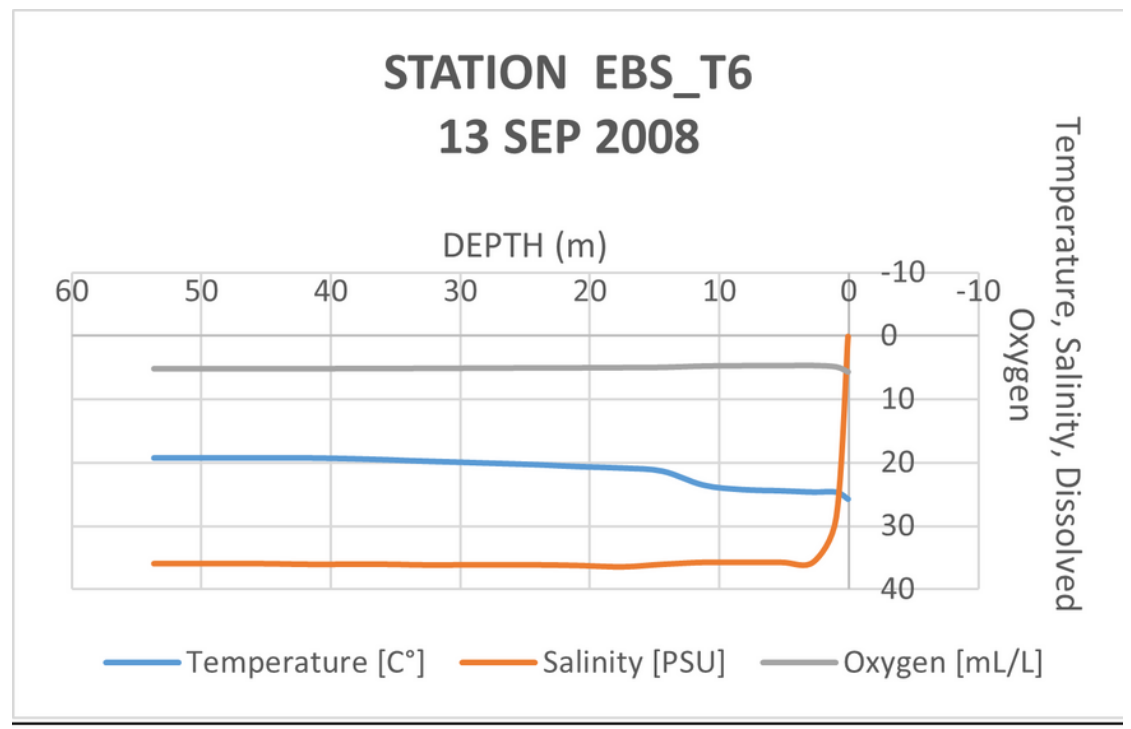

\section{STATION EBS_T4}

\section{SEP 2008}

Temperature $\left[\mathrm{C}^{\circ}\right] \longrightarrow$ Salinity $[\mathrm{PSU}]=$ Oxygen[mL/L]

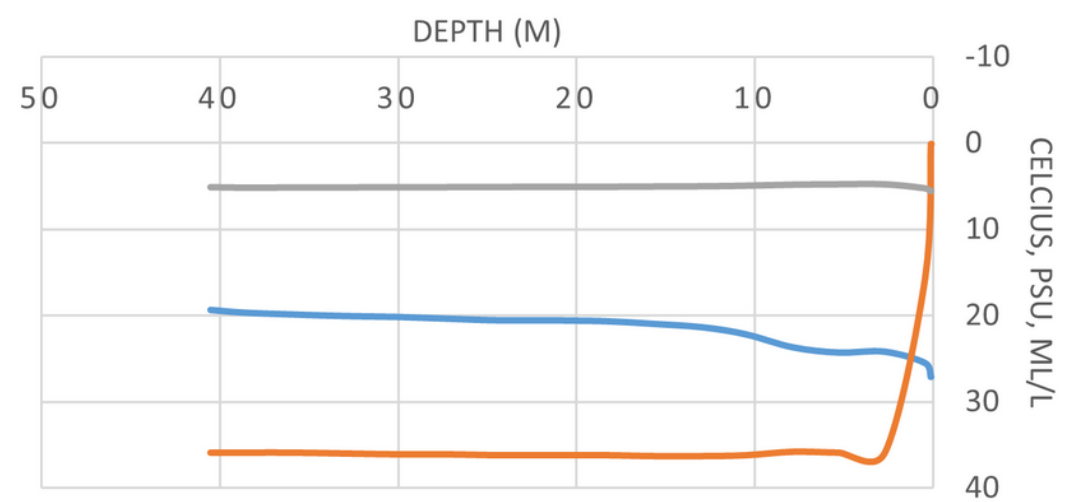

Figure 15

Hydrographic data. (a) Graph of EBS Station T6; (b) Graph of EBS Station T4 from EIA EBS by ERM/TGL 


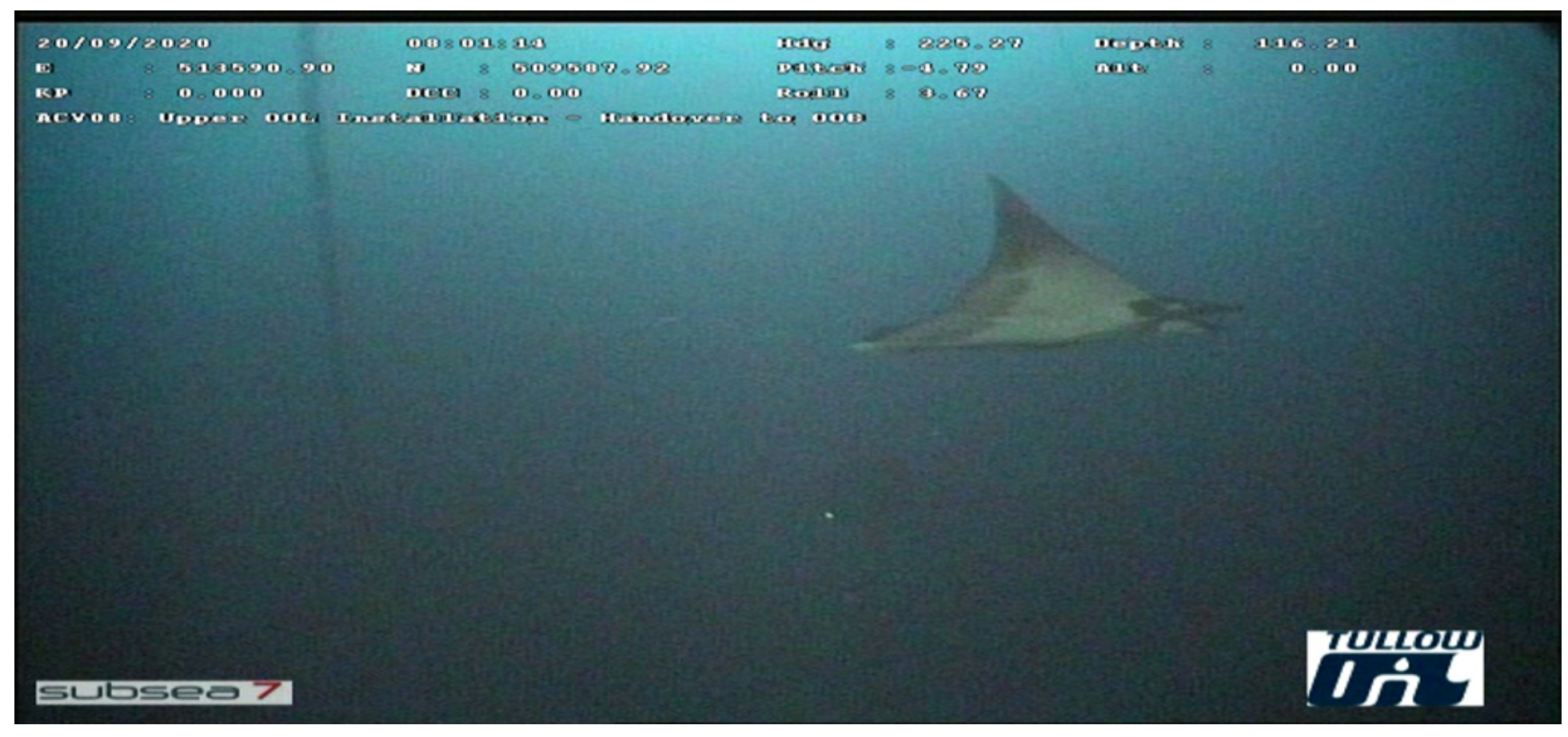

Figure 16

Mantra observed subsea. Courtesy Subsea 7 ROV

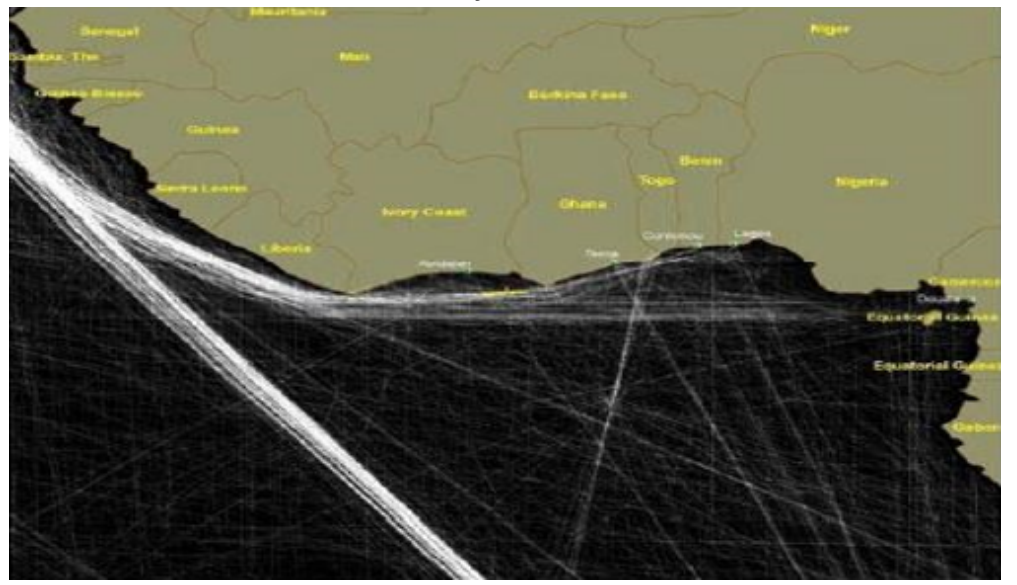

Figure 17

West Africa Shipping Lane (ERM/TGL, 2009)

\section{Supplementary Files}

This is a list of supplementary files associated with this preprint. Click to download.

- JANMARJUBWINDDATA.xls

- JANMARJUBWINDDATA.sam

- 10FEB2020ANALYSISOFTEMPSALINITY.xIsX

- ENVIRONMENTALDATA2020.xIsx 